\title{
The promising role of noncoding RNAs in cancer-associated fibroblasts: an overview of current status and future perspectives
}

\author{
Zengli Fang ${ }^{1,2,3,4 \dagger}$, Jin $X u^{1,2,3,4 \dagger}$, Bo Zhang ${ }^{1,2,3,4 \dagger}$, Wei Wang ${ }^{1,2,3,4}$, Jiang Liu" ${ }^{1,2,3,4}$, Chen Liang ${ }^{1,2,3,4}$, Jie Hua ${ }^{1,2,3,4}$,
} Qingcai Meng ${ }^{1,2,3,4^{*}}$, Xianjun $\mathrm{Yu}^{1,2,3,4^{*}}$ and Si Shi $i^{1,2,3,4^{*}}$ (1)

\begin{abstract}
As the most important component of the stromal cell population in the tumor microenvironment (TME), cancerassociated fibroblasts (CAFs) are crucial players in tumor initiation and progression. The interaction between CAFs and tumor cells, as well as the resulting effect, is much greater than initially expected. Numerous studies have shown that noncoding RNAs (ncRNAs) play an irreplaceable role in this interplay, and related evidence continues to emerge and advance. Under the action of ncRNAs, normal fibroblasts are directly or indirectly activated into CAFs, and their metabolic characteristics are changed; thus, CAFs can more effectively promote tumor progression. Moreover, via ncRNAs, activated CAFs can affect the gene expression and secretory characteristics of cells, alter the TME and enhance malignant biological processes in tumor cells to contribute to tumor promotion. Previously, ncRNA dysregulation was considered the main mechanism by which ncRNAs participate in the crosstalk between CAFs and tumor cells. Recently, however, exosomes containing ncRNAs have been identified as another vital mode of interaction between these two types of cells, with a more direct and clear function. Gaining an in-depth understanding of ncRNAs in CAFs and the complex regulatory network connecting CAFs with tumor cells might help us to establish more effective and safer approaches for cancer therapies targeting ncRNAs and CAFs and offer new hope for cancer patients.
\end{abstract}

Keywords: Noncoding RNA, MicroRNA, Long noncoding RNA, Cancer-associated fibroblasts, Tumor microenvironment, Cancer, Exosome, Cell-cell interaction

\section{Introduction}

Tumor progression is not an independent event related only to the biological characteristics of tumor cells but instead is a process affected and modulated by many factors. One of these factors, the tumor microenvironment (TME), is vital for tumor initiation, progression, metastasis, immunosuppression and therapeutic resistance $[1$, 2]. The TME consists of cancer-associated fibroblasts

\footnotetext{
*Correspondence: mengqingcai@fudanpci.org; yuxianjun@fudanpci.org; shisi@fudanpci.org

†Zengli Fang, Jin Xu, and Bo Zhang contributed equally to this work.

${ }^{1}$ Department of Pancreatic Surgery, Fudan University Shanghai Cancer Center, No. 270 Dong'An Road, Shanghai 200032, China

Full list of author information is available at the end of the article
}

(CAFs), macrophages, myeloid-derived suppressor cells (MDSCs), lymphocytes, antigen-presenting cells and other tumor-associated stromal cells, as well as microvessels, lymphatic vessels, nerves, infiltrating biomolecules and extracellular matrix (ECM) components [3, 4]. As the key components among these constituents, CAFs are abundant in the TME (especially in pancreatic cancer) and interact closely with tumor cells [5]. Fibroblasts are a population of spindle-shaped cells of mesenchymal origin that exhibit distinct phenotypes according to the microenvironment. Fibroblasts activated during wound healing are called "myofibroblasts," while those activated in tumor tissues are defined as CAFs [6, 7]. Unlike normal fibroblasts (NFs), most CAFs have a myofibroblastic

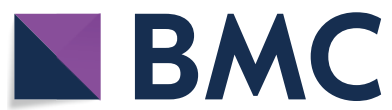

(c) The Author(s) 2020. Open Access This article is licensed under a Creative Commons Attribution 4.0 International License, which permits use, sharing, adaptation, distribution and reproduction in any medium or format, as long as you give appropriate credit to the original author(s) and the source, provide a link to the Creative Commons licence, and indicate if changes were made. The images or other third party material in this article are included in the article's Creative Commons licence, unless indicated otherwise in a credit line to the material. If material is not included in the article's Creative Commons licence and your intended use is not permitted by statutory regulation or exceeds the permitted use, you will need to obtain permission directly from the copyright holder. To view a copy of this licence, visit http://creativecommons.org/licenses/by/4.0/. The Creative Commons Public Domain Dedication waiver (http://creativeco mmons.org/publicdomain/zero/1.0/) applies to the data made available in this article, unless otherwise stated in a credit line to the data. 
phenotype (termed myCAFs) with characteristics such as overexpression of $\alpha$-smooth muscle actin ( $\alpha$-SMA) and fibroblast activation protein (FAP) and are in a state of active proliferation and metabolism [8]. Additionally, some CAFs are defined as inflammatory CAFs (iCAFs) due to their secretory properties and inflammatory regulatory function [9]. CAFs contribute substantially to tumor progression in multifarious manners. As the main source of collagen-producing cells in the TME, CAFs provide mechanical support for tumor tissues and regulate the growth and invasion of tumor cells by synthesizing or remodeling the structure of the ECM [10]. Importantly, CAFs can also mediate the interplay between tumor cells and stromal cells by secreting a variety of growth factors, cytokines, chemokines and exosomes, thus affecting the key steps in tumor malignant progression [11, 12]. However, the specific mechanisms through which CAFs play these roles need further exploration.

Only $<2 \%$ of the transcripts in the human genome encode proteins; the remaining $98 \%$ are noncoding RNAs (ncRNAs). Because they lack complete open reading frames (ORFs), ncRNAs cannot be templates for protein synthesis, but they contribute significantly to the regulation of epigenetic modification levels. NcRNAs are classified into two main categories according to their length: small noncoding RNAs (sncRNAs) and long noncoding RNAs (lncRNAs). SncRNAs are usually less than 200 nucleotides (nt) in length and include microRNAs (miRNAs), piwi-interacting RNAs (piRNAs), small interfering RNAs (siRNAs), and so on. MiRNAs are a class of sncRNAs with a length of approximately $22 \mathrm{nt}$ that mediate inhibition of gene translation or degradation of mRNA by binding to the $3^{\prime}$ untranslated region ( $3^{\prime}$ UTR) or ORFs of their target mRNA, thereby regulating the expression of target proteins at the posttranscriptional level [13]. NcRNAs with a transcript length of more than $200 \mathrm{nt}$ are defined as lncRNAs; lncRNAs regulate gene expression at the transcriptional or posttranscriptional level through interactions with proteins or nucleic acids, thus affecting many biological processes [14]. Circular RNAs (circRNAs) are a new class of endogenous ncRNAs with a single-stranded, closed-loop structure that lacks $5^{\prime}$ and $3^{\prime}$ ends and a poly(A) tail, which makes circRNAs more stable than linear RNAs [15]. CircRNAs act as miRNA sponges or transcriptional regulators or bind to RNAbinding proteins (RBPs) to regulate gene expression [16]. NcRNAs participate in many physiological and pathological processes in the body, and ncRNA dysregulation is closely related to the development of diseases such as cardiovascular diseases, neurological diseases and cancer [17-20]. During tumor progression, ncRNAs can regulate the proliferation, stemness, metabolism, differentiation, apoptosis, invasion and drug resistance of tumor cells, while their dysregulation can be affected by gene mutations or epigenetic changes in tumor cells [21-23]. More importantly, ncRNAs can mediate the interplay between tumor cells and stromal cells via various mechanisms to promote or suppress tumor progression.

The role of ncRNAs in tumor cells has been confirmed by extensive research, and their effects on the TME have received increasing attention. Accumulating evidence shows that miRNAs are involved in the transformation of NFs to CAFs and modulate the crosstalk between CAFs and tumor cells. Although the research on the role of IncRNAs in CAFs is not as extensive and in-depth as that on the role of miRNAs, it has achieved remarkable advances. Importantly, tumor cells and CAFs can communicate more directly and effectively by producing exosomes packed with ncRNAs, which can be taken up by adjacent or distant cells to further contribute to tumor progression. To date, no study has investigated the function of other types of ncRNAs, such as circRNAs, in CAFs. Thus, this review focuses on the studies of miRNAs and lncRNAs. In this review, we introduce the origins and heterogeneity of CAFs; focus on the roles of miRNAs and lncRNAs in the formation and metabolic reprogramming of CAFs as well as on the contribution of miRNAs and lncRNAs in CAFs to aspects of tumor progression, such as proliferation, stemness, angiogenesis, metastasis and therapeutic resistance; and discuss the possible therapeutic targets among these mechanisms.

\section{Origins of CAFs}

CAFs are a heterogeneous population of cells, and their heterogeneity might be attributable to their numerous potential cellular precursors (Fig. 1) [6, 9]. Tissue-resident NFs can be activated as CAFs under the stimulatory effects of the TME. Transforming growth factor- $\beta$ (TGF- $\beta$ ), epidermal growth factor (EGF), platelet-derived growth factor (PDGF), fibroblast growth factor 2 (FGF2), sonic hedgehog $(\mathrm{SHH})$, bone morphogenetic protein (BMP) and reactive oxygen species (ROS) are pivotal regulators of fibroblast activation [6, 24-26]. For example, quiescent pancreatic stellate cells (PSCs) and hepatic stellate cells (HSCs), tissue-resident fibroblasts of the pancreas and liver, can acquire a myofibroblast-like phenotype including characteristics such as $\alpha$-SMA expression when activated by TGF- $\beta$ and PDGF and can then transform into CAFs $[27,28]$.Mesenchymal stem cells (MSCs) might be another source of CAFs [29]. By fluorescent protein labeling, Raz et al. found that bone marrow-derived MSCs can be recruited and reprogrammed into different CAF subsets [30]. In breast cancer, osteopontin mediates the MZF1-TGF- $\beta 1$-dependent differentiation of MSCs into CAFs [31]. HOXA9 expressed in epithelial ovarian cancer cells induces adipose and bone 


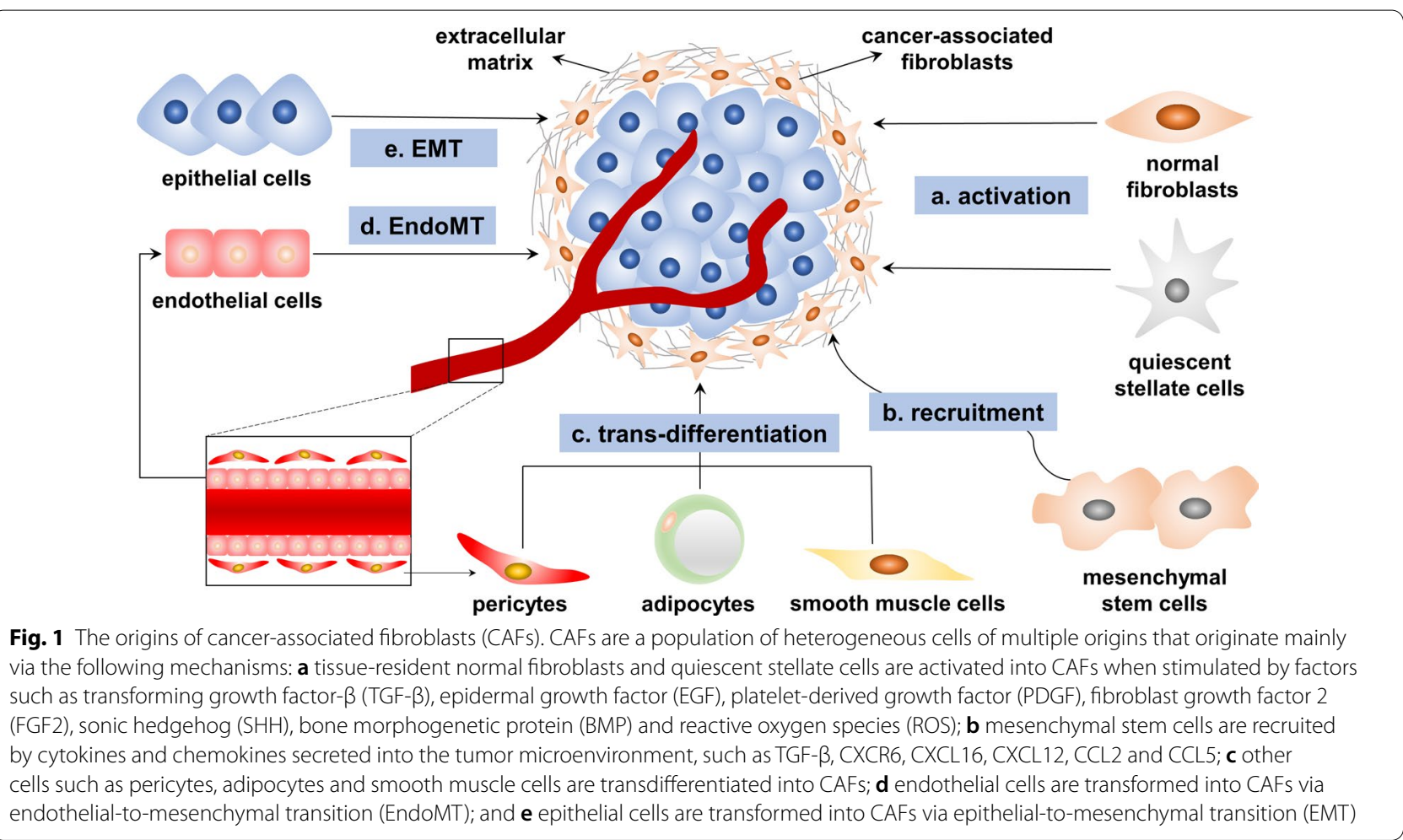

marrow-derived MSCs to acquire the CAF phenotype through transcriptional activation of the gene encoding TGF- $\beta 2$ [32]. These studies indicated that TGF- $\beta$ plays an important role in this process. In prostate cancer, MSCs can differentiate into CAFs after activation by $\mathrm{C}-\mathrm{X}-\mathrm{C}$ motif chemokine receptor 6 (CXCR6) and its ligand CXCL16 [33]. Additionally, the recruitment and transformation of MSCs also depend on CXCL12, CCL2 and CCL5 secreted in the TME [29,34]. CAFs might also be differentiated from nonfibroblast lines such as epithelial cells [35, 36], endothelial cells [37], adipocytes [38], pericytes [39] and smooth muscle cells [40]. Epithelial cells and endothelial cells transdifferentiate into CAFs through epithelial-to-mesenchymal transition (EMT) or endothelial-to-mesenchymal transition (EndoMT), after which they express an abundance of mesenchymal markers such as $\alpha$-SMA and FAP $[41,42]$.

In summary, the CAF population is composed of multiple cell subsets and may have diverse phenotypes and functions. However, overall, the exact origins of CAFs have not been fully clarified. CAFs express a variety of proteins, such as $\alpha$-SMA, PDGF receptor- $\alpha / \beta$ (PDGFR $\alpha / \beta)$, FAP, fibronectin, kindlin-2, tenascin $C$ and integrin- $\alpha 11$ [43-46]. However, the expression levels of these proteins vary among different CAF subsets, and none of these proteins is specific to NFs or CAFs [47]. To further identify the origins of CAFs, researchers have used mouse models with genetic lineage tracing and fluorescence tagging, which can suitably describe the models of disease progression [30,48]. Although these models have undergone technical progress, identifying the exact biological origin of CAFs remains difficult because of the lack of specific markers for NFs and CAFs $[49,50]$.

\section{Heterogeneity and plasticity of CAFs}

As previously described, the CAF population is composed of multiple cell subsets, which typically exhibit heterogeneity. In pancreatic cancer, a study grouped CAFs into two subsets: myCAFs and iCAFs [9]. MyCAFs are located adjacent to cancer cells, are characterized by a high level of $\alpha$-SMA expression and exhibit a matrixproducing contractile phenotype. In contrast, iCAFs are located further from cancer cells and are recognized by their high expression of tumor-promoting cytokines and chemokines such as interleukin-6 (IL-6). Further, Elyada et al. confirmed the existence of myCAFs and iCAFs in pancreatic cancer by single-cell RNA sequencing [51]. Interestingly, in that study, the researchers also identified a new subset of CAFs and defined these cells as "antigen-presenting CAFs" (apCAFs), which express MHC-II and CD74 but do not express classical costimulatory molecules. ApCAFs can activate CD4+ T cells in an antigen-specific manner, indicating their immunoregulatory ability. In another study, CAFs in pancreatic 
cancer were divided into at least four subtypes based on a transcriptomic analysis [52]. Subtype A cells labeled with periostin were found in the invasive front of the primary tumor, which is important for the formation of tumor capsule and metastasis. Subtype B cells labeled with myosin-11 were enriched in larger tumors and were associated with lymph node metastasis and poor prognosis. Subtype C cells labeled with podoplanin were enriched in a variety of immune-related pathways and seem to have an immunogenic profile and are related to a better prognosis. In addition, in breast cancer, a recent study identified four CAF subpopulations (S1-4) with different distributions and unique properties among breast cancer subtypes [53]. Among these subpopulations, S1-CAFs, which overexpress FAP, can attract $\mathrm{T}$ cells and promote their differentiation into Treg cells, thus contributing to an immunosuppressive TME. In contrast to promoting tumor growth, some subtypes of CAFs may be able to suppress tumor progression. For example, Rhim et al. found that the number of $\alpha$-SMA + myofibroblasts was decreased in the TME of mice with Shh-deficient pancreatic ductal adenocarcinoma (PDAC), resulting in poor differentiation and stronger invasiveness [54]. Additionally, Ozdemir et al. demonstrated that depletion of $\alpha$-SMA + fibroblasts leads to more invasive and undifferentiated tumors [50]. In some cases, different subtypes of CAFs in the same TME may have opposite effects on cancer progression. For instance, two CAF subtypes that differentially express CD146 play conflicting roles in the responsiveness of breast cancer to endocrine therapy [55]. Importantly, Givel et al. grouped CAFs into four subpopulations in mesenchymal high-grade serous ovarian cancer based on CD29, FAP, FSP1, and SMA protein levels [56]. CAF-S1 and CAF-S4 fibroblasts were defined as activated CAFs because of their high SMA expression levels, while CAF-S2 and CAF-S3 fibroblasts were considered to be nonactivated CAFs with low levels of SMA. CAF-S1 fibroblasts can improve the survival of $\mathrm{CD} 25^{+} \mathrm{FOXP}^{+}{ }^{+} \mathrm{T}$ lymphocytes and result in immunosuppression, which is mediated by the high expression of CXCL12 $\beta$ in CAF-S1. The different levels of CXCL12 $\beta$ in CAF-S1 and CAF-S4 fibroblasts lead to different functions among CAF subpopulations, which ultimately affects the prognosis of cancer patients [56, 57].

Due to the heterogeneous phenotypes, functions and spatial distribution of CAFs, researchers began to consider whether different subtypes can be interconvertedthat is, whether CAFs exhibit plasticity. CAFs were found to be able to transition from the $\alpha$-SMA+ and IL-6-producing state through TGF- $\beta$-dependent manipulation [58]. Additionally, prostate CAFs can acquire a tumor-like phenotype via a novel lipid-microtubuleorganizing center (MTOC) axis regulated by pigment epithelium-derived factor (PEDF) [59]. In pancreatic cancer, the activation of the JAK/STAT signaling pathway induces the iCAFs phenotype, while JAK inhibitors can transform iCAFs into myCAFs; TGF- $\beta$ signaling can also antagonize IL1-induced JAK/STAT signaling, thus inhibiting the iCAFs phenotype [60]. The phenotypic and functional transformation of CAFs reflects their instability and plasticity, which is a potential target for cancer therapy. However, considering the profound adaptability of fibroblasts to direct, local and long-term stimulatory factors, it is difficult to determine whether targeting specific CAF subsets will have lasting effects [61]. Many signaling pathways, such as EGFR signaling, Wnt signaling, Hippo signaling and TGF- $\beta$ signaling, have been shown to play a key role in the regulation of CAF heterogeneity [57]. These signaling pathways may be another important direction for CAF-targeted therapy, and further studies of these pathways may help improve our understanding of CAF heterogeneity.

\section{MiRNAs in CAFs}

\section{Biosynthesis and mechanisms of miRNAs}

MiRNAs are a class of sncRNAs encoded by endogenous genes with a length of approximately $22 \mathrm{nt}$. The human genome contains more than 2000 miRNAs, approximately $70 \%$ of which are related to protein-coding genes and are cotranscribed [62]. The miRNA biosynthesis pathway is complex. The miRNA host gene is transcribed to produce a primary RNA (primiRNA), which has a hairpin structure and a poly(A) tail, by either RNA polymerase II or RNA polymerase III [63, 64]. In the nucleus, the pri-miRNA is processed first by a protein complex consisting of two proteins, Drosha and DiGeorge critical region 8 (DGCR8, also known as Pasha), which are an RNase III protein and a double-stranded RNA-binding protein, respectively. DGCR8 positions the Drosha cutting site 11 base pairs (bp) from the base of the hairpin stem, and the pri-miRNA is then processed into a 60-70 nt precursor miRNA (pre-miRNA) by Drosha [65, 66]. Later, the pre-miRNA is transported from the nucleus to the cytoplasm with the assistance of Exportin-5 in complex with Ran-GTP $[67,68]$. In the cytoplasm, the premiRNA is recognized by Dicer, a member of the RNase III enzyme family, and is processed into a $20 \mathrm{nt}$ doublestranded miRNA via cutting and modification of the stem-loop structure [69]. The resulting double-stranded miRNA binds to Argonaute proteins to form the RNAinduced silencing complex (RISC), in which one of the miRNA strands binds to the $3^{\prime}$ UTR of the target mRNA through the incorporation of protein complexes, while the other miRNA strand is degraded or released $[13,70]$.

The regulatory effect of miRNAs on gene expression occurs at the posttranscriptional level through two main 
mechanisms, which depend on the complementarity between the miRNA and target gene mRNA sequences. If the miRNA sequence is nearly perfectly complementary to that of the target mRNA-for example, in plantsthe miRNA forms a completely complementary double-stranded RNA with the sequence in the ORF of the mRNA. Then, the RISC degrades this double-stranded mRNA and silences gene expression posttranscriptionally. Otherwise, in most cases, the miRNA forms an incompletely complementary hybrid double-stranded RNA with the $3^{\prime}$ UTR sequence of the target mRNA, and the RISC binds tightly to this hybrid RNA to specifically inhibit gene expression [13, 71, 72]. Importantly, one miRNA can regulate multiple mRNAs and, conversely, one mRNA can be targeted by several miRNAs [62]. In addition, as the understanding of miRNAs has deepened, many unconventional functions of miRNAs have been gradually discovered, such as binding to the $5^{\prime}$ UTR of mRNAs or binding directly to Toll-like receptors [73-75].

\section{MiRNAs in the formation and activation of CAFs}

Tumor progression requires stromal support to maintain tumor cell proliferation, migration and metastasis [4]. For tumor cells, it is necessary to reprogram inactivated fibroblasts into tumor-promoting CAFs to maintain tumor progression. The activation and maintenance of
CAFs may be related to epigenetic regulation [76], gene mutation [77, 78] and cytokine stimulation in the TME [79]. MiRNA dysregulation is vital to these processes and has been observed in CAFs in various cancers, including breast cancer [80], ovarian cancer [81] and lung cancer [82]. Thus, miRNAs are considered to be pivotal regulatory factors for the formation and activation of CAFs, and many studies have confirmed this belief (Table 1).

Induction by growth factors, cytokines and chemokines is an important pathway of CAF formation and activation. It was found that colorectal cancer-derived TGF- $\beta$ increases the expression of miR-21, which upregulates $\alpha$-SMA and promotes the activation of CAFs [83]. A recent study in an orthotopic transplantation model proved again that high expression of miR21 in the stroma can allow the conversion of NFs into SMA + CAFs and affect tumor growth by activating the TGF- $\beta$ signaling pathway [84]. In NFs treated with exogenous TGF- $\beta$, the decrease in $\mathrm{miR}-200 \mathrm{~b} / \mathrm{c}$ expression and the increase in miR-221b expression induce DNMT3B expression at a stable and high level. Promoter methylation of miR-200s is induced by DNMT3B, leading to a decrease in miR-200s expression, which results in the activation of CAFs [85]. IL-6 is a chemokine present in the TME that may also be crucial for CAF activation [86]. $\mathrm{Li}$ et al. reported that in gastric cancer, miR-149 inhibits

Table 1 MicroRNAs involved in the formation and activation of cancer-associated fibroblasts

\begin{tabular}{|c|c|c|c|c|c|}
\hline Cancer type & miRNA & Expression & Upstream signaling & Target molecules or pathways & References \\
\hline \multicolumn{6}{|l|}{ miRNA dysregulation } \\
\hline Breast cancer & $\begin{array}{l}\mathrm{miR}-200 \mathrm{~b} / \mathrm{c} \\
\mathrm{miR}-221 \mathrm{~b}\end{array}$ & $\begin{array}{l}\downarrow \\
\uparrow\end{array}$ & TGF- $\beta$ & DNMT3B, miR-200s & {$[85]$} \\
\hline Breast cancer & miR-21 & $\uparrow$ & CCL18/NF-KB & PTEN/AKT axis & {$[90]$} \\
\hline Breast cancer & $\operatorname{miR}-222$ & $\uparrow$ & - & LBR & {$[202]$} \\
\hline Breast cancer & miR-200b/c & $\downarrow$ & - & IKK $\beta / N F-K B$ axis & {$[203]$} \\
\hline Breast cancer & miR-200s & $\downarrow$ & TGF- $\beta 1$ & Fli-1, TCF12 & {$[138]$} \\
\hline Colorectal cancer & miR-21 & $\uparrow$ & TGF- $\beta$ & - & {$[83]$} \\
\hline Gastric cancer & miR-149 & $\downarrow$ & - & $\mathrm{IL}-6$ & {$[87]$} \\
\hline Lung cancer & $\begin{array}{l}\text { miR-1, miR-206 } \\
\text { miR-31 }\end{array}$ & $\begin{array}{l}\downarrow \\
\uparrow\end{array}$ & - & FOXO3a/NEGFA/CCL2 axis & {$[89]$} \\
\hline Pancreatic cancer & miR-21 & $\uparrow$ & - & TGF- $\beta$ & {$[84]$} \\
\hline Prostate cancer & miR-205 & $\downarrow$ & - & $\mathrm{IL}-6$ & {$[88]$} \\
\hline- & miR-21 & $\uparrow$ & - & Smad7/TGF- $\beta 1$ & {$[204]$} \\
\hline \multicolumn{6}{|l|}{ Exosomal miRNA } \\
\hline Breast cancer & miR-125b & $\uparrow$ & - & TP53INP1/TP53 & {$[95]$} \\
\hline Breast cancer & miR-146a & $\uparrow$ & - & TXNIP/Wnt axis & {$[205]$} \\
\hline Breast cancer & miR-9 & $\uparrow$ & - & - & {$[206]$} \\
\hline Hepatocellular carcinoma & miR-21 & $\uparrow$ & - & PTEN/PDK1/AKT axis & {$[96]$} \\
\hline Hepatocellular Carcinoma & miR-1247-3p & $\uparrow$ & - & B4GALT3, $\beta 1$-integrin/NF-KB axis & {$[97]$} \\
\hline Melanoma & $\operatorname{miR}-211$ & $\uparrow$ & - & IGF2R, MAPK & {$[98]$} \\
\hline Pancreatic cancer & miR-155 & $\uparrow$ & - & TP53INP1 & {$[207]$} \\
\hline
\end{tabular}


the activation of fibroblasts by targeting IL-6 mRNA and reducing its expression [87]. In prostate cancer, miR-205 inhibits tumor-driven fibroblast activation by reducing the secretion of proinflammatory cytokines such as IL-6 [88]. In addition, Shen et al. revealed that CCL-2 is also a target of miRNA and is crucial for CAF activation. Downregulation of miR-1 and miR-206 and upregulation of miR-31 reprogram NFs into CAFs by mediating FOXO3a/VEGFA/CCL2 signaling [89]. Regarding breast cancer, tumor-associated macrophages induce myofibroblast differentiation and increase the expression of

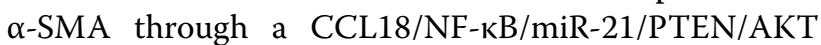
signaling axis [90].

In addition, miRNAs contained in exosomes are pivotal for the formation and activation of CAFs. Exosomes are membrane-coated vesicles derived from the endosomal system $[91,92]$ that are $30-100 \mathrm{~nm}$ in diameter and contain nucleic acids, proteins and lipids to mediate communication among cancer cells, CAFs and other cells in the TME [93, 94]. Recently, Vu et al. confirmed by RNA sequencing that miR-125b is secreted by the mouse triple negative breast cancer cell lines 4T1 and 4TO7, and TP53INP1 suppression induced by exosomal miR-125b is one cause of fibroblast activation in a mouse tumor model [95]. Further, exosomal miR-125b also activates human fibroblasts by suppressing the expression of TP53INP1 and TP53. In hepatocellular carcinoma (HCC), exosomal miR-21 secreted from HCC cells targets PTEN directly, leading to the activation of PDK1/AKT signaling in HSCs and the transformation of these cells into CAFs [96]. Moreover, exosomal miR-1247-3p secreted from highly metastatic HCC cells targets B4GALT3 and activates the $\beta 1$-integrin/NF- $\mathrm{kB}$ axis in fibroblasts, thus resulting in the transformation of NFs into CAFs [97]. In melanoma, a study demonstrated that the MAPK signaling pathway is activated under the effect of melanosome-derived miR211 via inhibition of the tumor suppressor IGF2R, resulting in the acquisition of a CAF phenotype by NFs [98].

\section{MiRNAs in the metabolic reprogramming of CAFs}

CAFs have been found to secrete a large number of metabolites, including L-lactate, ketone bodies, fatty acids, amino acids and tricarboxylic acid (TCA) cycle intermediates, which can be taken up by cancer cells and support their growth [11, 99-101]. Many studies have reported that cancer cells modulate the metabolic reprogramming of CAFs through ROS and miRNAs; this process is described as the reverse Warburg effect and plays an important role in cancer progression [102-104].

MiR-210 is considered to be a hypoxia-related miRNA. In fibroblasts cultured under hypoxia, the expression of miR-210 was found to be increased sixfold. Overexpressed miR-210 can participate in the metabolic reprogramming of CAFs, thus promoting the production of L-lactate, ketone bodies and other metabolites to promote the growth of cancer cells [105]. Zhang et al. revealed that miR-424 is related to TGF- $\beta$-induced downregulation of IDH3 $\alpha$ (a key rate-limiting enzyme in the TCA cycle) in CAFs. Downregulation of IDH3 $\alpha$ leads to metabolic reprogramming from oxidative phosphorylation to glycolysis in CAFs and increases the expression of glycolysis-related enzymes such as GLUT1, HK2 and PFKM. Moreover, in CAFs overexpressing miR-424, lactate production and glucose uptake can be increased and oxygen consumption can be suppressed via an increase in HIF1 $\alpha$ stability [106]. Regarding exosome-derived miRNAs, Yan et al. showed that the metabolic characteristics of CAFs are changed by exosomal miR-105 according to different metabolic environments through activation of the myc signaling pathway. After miR-105-mediated reprogramming, CAFs exhibit enhanced glucose and glutamine metabolism to fuel neighboring cancer cells when nutrients are adequate. Under nutrient-deficient conditions and accumulation of metabolic byproducts, CAFs can convert metabolic waste products into energy-rich metabolites [103]. This study further demonstrates the importance of miRNAs in regulating the metabolism of CAFs.

\section{MiRNAs in the effect of CAFs on cancer cells}

The crosstalk between cancer cells and the TME is considered to be essential in the progression of cancer [107]. The interaction of CAFs and cancer cells is mediated through a complex signaling network, and each cell type affects the function of the other via synergistic or antagonistic signaling axes [8]. Numerous in vitro and in vivo experiments have revealed that CAFs can influence the proliferation, stemness, metabolism, angiogenesis, metastasis and therapeutic resistance of cancer by secreting cytokines, growth factors and exosomes [6, 108]. Furthermore, accumulating evidence has shown that miRNAs are crucial for the effects of CAFs on cancer cells (Fig. 2 and Table 2). In this section, these studies are reviewed.

\section{Proliferation}

The proliferation of cancer cells is the most important and basic step in tumor progression. As mentioned earlier, CAFs can regulate the proliferation of cancer cells by secreting various cytokines or chemokines under the regulation of miRNAs. For example, signaling through the TGF- $\beta 1 / \mathrm{DNMT} 3 \mathrm{~B} / \mathrm{miR}-141$ axis can increase the expression of TCF12, which promotes CXCL12 secretion by CAFs, thus activating the c-myc/CyclinD1 signaling pathway in cancer cells and finally enhancing their proliferation [109]. In addition, Zhang et al. found that 


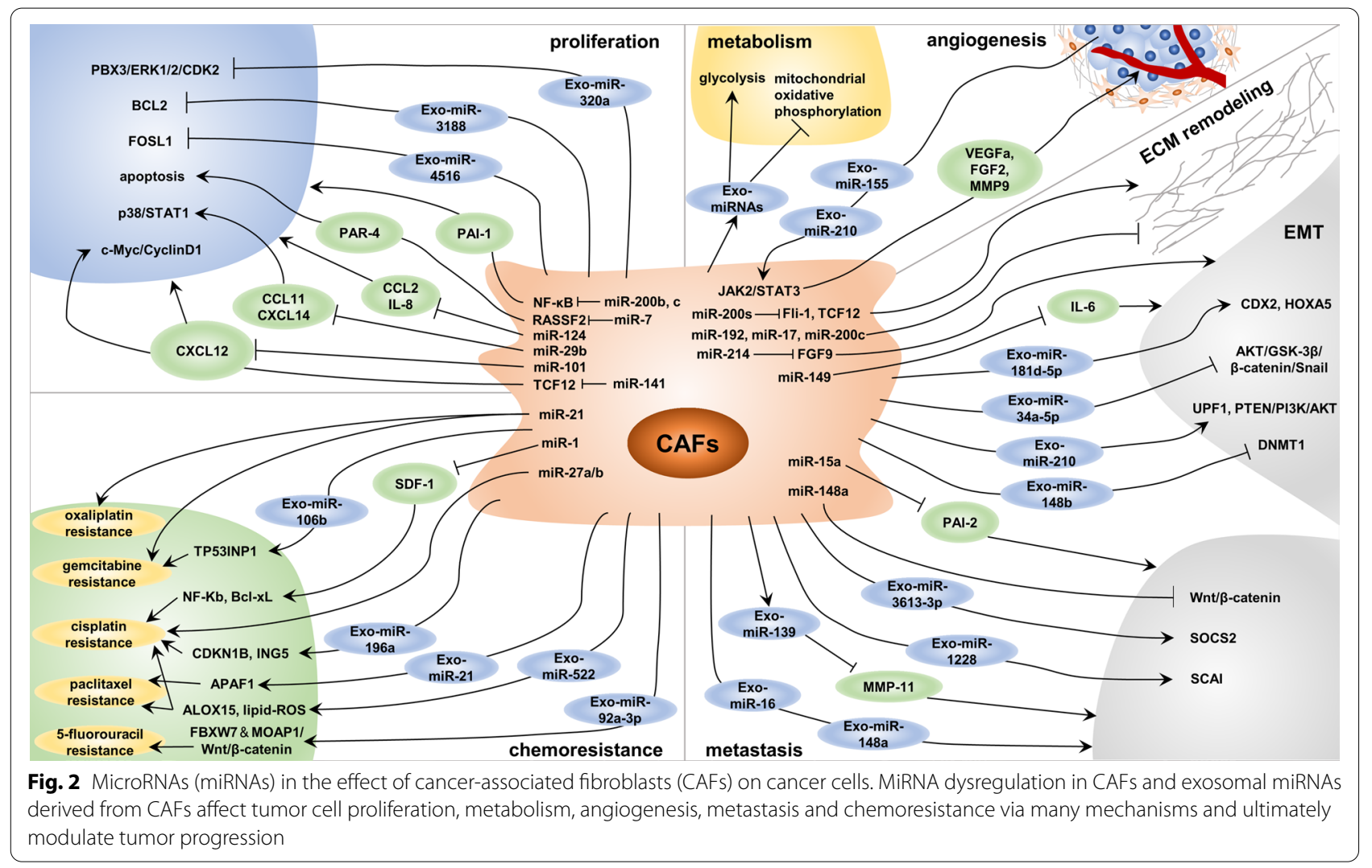

miR-101 in CAFs inhibits tumor growth and metastasis by targeting CXCL12 [82]. In oral carcinoma, downregulation of miR-124 in CAFs facilitates the proliferation of cancer cells by targeting CCL2 and IL-8 [110]. Importantly, the increases in the proliferation and drug resistance of breast cancer cells are related to downregulation of miR-29b in CAFs, which leads to increased secretion of CCL11 and CXCL14 possibly partially via activation of the p38-STAT1 pathway in cancer cells [111].

FGF-2 and its receptor FGFR1 can enhance tumor cell proliferation and migration by acting on stromal cells and cancer cells. Musumeci et al. revealed that downregulation of miR-15 and miR-16 in CAFs promotes tumor growth by reducing the posttranscriptional inhibition of FGF-2 and FGFR1 [112]. The expression of plasminogen activator inhibitor 1 (PAI-1), an important intermediary in the crosstalk between CAFs and epithelial tumor cells, in CAFs is closely related to the miR-200b, $c / N F-\kappa B$ axis and affects the proliferation of cancer cells [113]. In addition, miRNAs can regulate the ability of CAFs to promote cancer cell apoptosis, thus affecting tumor growth. In head and neck cancers, overexpression of miR-7 in CAFs leads to downregulation of RASSF2, which greatly reduces the secretion of protease-activated receptor 4
(PAR-4), a proapoptotic factor in cancer cells, thus leading to enhancement of cancer cell proliferation [114].

The role of CAF-derived exosomal miRNAs in tumor proliferation has also received increasing attention. Kim et al. found that a decrease in the miR-4516 level in CAFderived exosomes enhances the proliferative ability of triple negative breast cancer cells by reducing the inhibition of FOSL1, a proliferation-related gene [115]. In head and neck cancers, loss of exosomal miR-3188 from CAFs promotes tumor growth by diminishing the inhibition of B-cell lymphoma 2 (BCL2) [116]. The miR-320a/PBX3 axis downregulates the expression of cyclin-dependent kinase 2 (CDK2) by targeting ERK1/2 to reduce MAPK signaling pathway activation, thus inhibiting the proliferation of HCC cells [117]. However, the amount of exosomal miR-320a derived from CAFs was found to be significantly decreased, which facilitated the growth and progression of $\mathrm{HCC}$. $\mathrm{Xu}$ et al. revealed that the growth and metastasis of gastric cancer cells are inhibited by exosomal miR-139 derived from CAFs, an effect mediated by downregulation of matrix metalloproteinase (MMP) 11 [118]. Interestingly, the level of CAF-derived exosomal miR-146a is increased by treatment with gemcitabine, while blocking exosome secretion can inhibit the proliferation and survival of PDAC cells [119]. 
Table 2 MicroRNAs in the effect of cancer-associated fibroblasts on cancer cells

\begin{tabular}{|c|c|c|c|c|c|c|}
\hline Cancer type & miRNA & Expression & Function & Upstream signaling & $\begin{array}{l}\text { Target molecules } \\
\text { or pathways }\end{array}$ & References \\
\hline \multicolumn{7}{|l|}{ miRNA dysregulation } \\
\hline Breast cancer & miR-141 & $\downarrow$ & Proliferation & TGF- $\beta 1 / D N M T 3 B$ & $\begin{array}{l}\text { TCF12/ CXCL12/ } \\
\text { C-Myc/CyclinD1 }\end{array}$ & [109] \\
\hline Breast cancer & miR-29b & $\downarrow$ & $\begin{array}{l}\text { Proliferation, Chemore- } \\
\text { sistance }\end{array}$ & - & $\begin{array}{l}\text { CCL11, CXCL14, p38/ } \\
\text { STAT1 }\end{array}$ & [111] \\
\hline Breast cancer & miR-200b, c & $\downarrow$ & $\begin{array}{l}\text { Proliferation, EMT, } \\
\text { Invasion }\end{array}$ & - & IKKß/NF-KB/PAI-1 & [113] \\
\hline Breast cancer & miR-200s & $\downarrow$ & Metastasis & - & Fli-1, TCF12 & [138] \\
\hline Cholangiocarcinoma & miR-15a & $\downarrow$ & Migration & - & PAl-2 & [140] \\
\hline Colorectal cancer & $\begin{array}{l}\text { miR-192, miR-17, miR- } \\
\text { 200c }\end{array}$ & $\downarrow$ & Invasion & - & ECM Associated Genes & [139] \\
\hline Colorectal cancer & $\operatorname{miR}-21$ & $\uparrow$ & $\begin{array}{l}\text { Proliferation, Invasion, } \\
\text { Chemoresistance }\end{array}$ & - & RECK, MMP2 & {$[83]$} \\
\hline Endometrial cancer & miR-148a & $\downarrow$ & Proliferation, Migration & - & $\begin{array}{l}\text { WNT10B, Wnt/ } \beta \text { - } \\
\text { catenin }\end{array}$ & [141] \\
\hline Esophageal cancer & miR-27a/b & $\uparrow$ & Chemoresistance & - & TGF- $\beta$ & [156] \\
\hline Gastric cancer & miR-214 & $\downarrow$ & EMT, Migration & - & FGF9 & [143] \\
\hline Gastric cancer & miR-149 & $\downarrow$ & Proliferation, EMT & $\begin{array}{l}\text { COX-2/PGE2, DNA } \\
\text { Hypermethylation }\end{array}$ & $\mathrm{IL}-6$ & {$[87]$} \\
\hline Head and Neck cancer & miR-7 & $\uparrow$ & Proliferation, Migration & - & RASSF2, PAR-4 & [114] \\
\hline Lung cancer & miR-101 & $\downarrow$ & Proliferation & - & CXCL12 & {$[82]$} \\
\hline Lung cancer & miR-1 & $\downarrow$ & $\begin{array}{l}\text { Proliferation, Chemore- } \\
\text { sistance }\end{array}$ & - & $\begin{array}{l}\text { SDF-1, CXCR4, NF-KB, } \\
\text { BCl-XL }\end{array}$ & {$[155]$} \\
\hline Oral carcinoma & miR-124 & $\downarrow$ & Proliferation, Migration & $\begin{array}{l}\text { DNA Hypermethyla- } \\
\text { tion }\end{array}$ & CCL2, IL-8 & {$[110]$} \\
\hline Pancreatic cancer & miR-21 & $\uparrow$ & Chemoresistance & - & Desmoplasia & [154] \\
\hline Prostate cancer & miR-15, miR-16 & $\downarrow$ & Proliferation, Migration & - & FGF-2, FGFR1 & [112] \\
\hline Prostate cancer & miR-210 & $\uparrow$ & Angiogenesis & Hypoxia & HUVECS & [105] \\
\hline \multicolumn{7}{|l|}{ Exosomal miRNA } \\
\hline Breast cancer & miR-4516 & $\downarrow$ & Proliferation & - & FOSL1 & [115] \\
\hline Breast cancer & miR-205 & $\downarrow$ & Angiogenesis & - & $\begin{array}{l}\text { YAP1/ IL-11, IL-15/ } \\
\text { STAT3 }\end{array}$ & [135] \\
\hline Breast cancer & miR-181d-5p & $\uparrow$ & Proliferation, EMT & - & CDX2/HOXA5 & {$[144]$} \\
\hline Breast cancer & miR-16, miR-148a & $\uparrow$ & Metastasis & FAK & - & [148] \\
\hline Breast cancer & miR-3613-3p & $\uparrow$ & Proliferation, Metastasis & - & SOCS2 & [149] \\
\hline Colorectal cancer & $\operatorname{miR}-21$ & $\uparrow$ & Metastasis & - & - & [151] \\
\hline Colorectal cancer & miR-92a-3p & $\uparrow$ & $\begin{array}{l}\text { EMT, Metastasis, Chem- } \\
\text { oresistance }\end{array}$ & - & $\begin{array}{l}\text { FBXW7 and MOAP1/ } \\
\text { Wnt/ } \beta \text {-catenin }\end{array}$ & [122] \\
\hline Endometrial cancer & miR-148b & $\downarrow$ & EMT, Metastasis & - & DNMT1 & [145] \\
\hline Gastric cancer & miR-139 & $\downarrow$ & Proliferation, Metastasis & - & MMP11 & [118] \\
\hline Gastric cancer & miR-522 & $\uparrow$ & $\begin{array}{l}\text { Metabolic Reprogram- } \\
\text { ming, Chemoresist- } \\
\text { ance }\end{array}$ & USP7/hnRNPA1 & ALOX15, lipid-ROS & [127] \\
\hline Head and neck cancer & miR-3188 & $\downarrow$ & Proliferation & - & $\mathrm{BCL} 2$ & [116] \\
\hline Head and neck cancer & miR-196a & $\uparrow$ & $\begin{array}{l}\text { Proliferation, Chemore- } \\
\text { sistance }\end{array}$ & hnRNPA1 & CDKN1B, ING5 & [157] \\
\hline $\begin{array}{l}\text { Hepatocellular carci- } \\
\text { noma }\end{array}$ & miR-320a & $\downarrow$ & $\begin{array}{l}\text { Proliferation, EMT, } \\
\text { Metastasis }\end{array}$ & - & PBX3/ERK1/2/CDK2 & {$[117]$} \\
\hline Lung cancer & miR-210 & $\uparrow$ & Angiogenesis & - & JAK2/STAT3 & {$[134]$} \\
\hline Lung cancer & miR-210 & $\uparrow$ & EMT, Migration & - & UPF1, PTEN/PI3K/AKT & [146] \\
\hline Melanoma & miR-155 & $\uparrow$ & Angiogenesis & - & SOCS1/JAK2/STAT3 & [133] \\
\hline Oral cancer & miR-34a-5p & $\downarrow$ & $\begin{array}{l}\text { Proliferation, EMT, } \\
\text { Metastasis }\end{array}$ & - & $\begin{array}{l}\text { AXL, AKT/GSK-3 } \beta / \beta- \\
\text { catenin/Snail }\end{array}$ & [147] \\
\hline
\end{tabular}


Table 2 (continued)

\begin{tabular}{|c|c|c|c|c|c|c|}
\hline Cancer type & miRNA & Expression & Function & Upstream signaling & $\begin{array}{l}\text { Target molecules } \\
\text { or pathways }\end{array}$ & References \\
\hline Osteosarcoma & miR-1228 & $\uparrow$ & Migration & - & SCAl & [150] \\
\hline Ovarian cancer & miR-21 & $\uparrow$ & $\begin{array}{l}\text { Invasion, Chemoresist- } \\
\text { ance }\end{array}$ & - & APAF1 & [158] \\
\hline Ovarian cancer & miR-98-5p & $\uparrow$ & Chemoresistance & - & CDKN1A & [159] \\
\hline Pancreatic cancer & miR-146a & $\uparrow$ & $\begin{array}{l}\text { Proliferation, Chemore- } \\
\text { sistance }\end{array}$ & Gemcitabine & - & [119] \\
\hline Pancreatic cancer & miR-106b & $\uparrow$ & Chemoresistance & - & TP53INP1 & [160] \\
\hline
\end{tabular}

\section{Stemness}

A population of cells in tumors play an irreplaceable role in tumor initiation, progression and therapeutic resistance, and have high potential for self-renewal and differentiation. These cells are defined as cancer stem cells (CSCs), and the acquisition and maintenance of their stemness are affected by many factors. The ability of CAFs to promote stemness has been widely studied in several tumor types $[12,120]$, but there are relatively few studies on the role of CAF-derived miRNAs in stemness regulation. In breast cancer, Donnarumma et al. identified three significantly upregulated miRNAs (miR-21-5p, miR-378e, and miR-143-3p) in CAF-derived exosomes by miRNA-seq [121]. CAF-derived exosomal miR-21-5p, miR-378e and miR-143-3p promote the stemness properties and EMT phenotype of tumor cells. Among them, miR-21-5p mainly plays a role in EMT induction, while miR-378e and miR-143-3p have a stronger effect on promoting stemness; however, the specific mechanisms of these processes are not clear. Another study found that exosomal miR-92a-3p enhances tumor stemness by targeting $F B X W 7$ and MOAP1 [122]. Additionally, by promoting the ubiquitination degradation of $\beta$-catenin and mitochondrial apoptosis, FBXW7 and MOAP1 can reverse the oncogenic effect of miR-92a-3p. In addition to the direct effect of CAF-derived miRNAs on stemness, CAFs can also indirectly promote stemness by regulating the expression of specific miRNAs in tumor cells [123]. Overall, miRNAs represent an important way for CAFs to regulate stemness and are worthy of more in-depth and extensive exploration.

\section{Metabolism}

Reprogramming of energy metabolism is a hallmark of cancer cells [124]. A well-characterized dysregulation of cancer metabolism is the Warburg effect, or aerobic glycolysis, which refers to the preference for oxygenindependent glycolysis and lactate secretion even in the presence of sufficient oxygen [125]. Although mitochondrial oxidative phosphorylation can produce more energy than glycolysis, cancer cells are thought to transfer glycolytic intermediates into biosynthetic pathways to produce amino acids, nucleotides and lipids that support cell growth via aerobic glycolysis [126]. As mentioned earlier, metabolic reprogramming CAFs can provide these metabolites for cancer cell growth. Moreover, CAFderived miRNAs play an important role in regulating cancer cell metabolism. Exosomes derived from CAFs can inhibit mitochondrial oxidative phosphorylation in cancer cells through miRNAs and the transfer of substrates, and glycolysis and glutamine-dependent reductive carboxylation are then upregulated in cancer cells [101]. A recent study demonstrated that exosomal miR522 derived from CAFs is a potential inhibitor of arachidonate lipoxygenase 15 (ALOX15), which is closely related to the production of lipid-ROS in gastric cancer [127]. These lines of evidence indicate that miRNA-regulated metabolic crosstalk between CAFs and cancer cells affects the progression of cancer via multifarious mechanisms. Improving our knowledge of these processes may open new avenues for the treatment of cancer.

\section{Angiogenesis}

Tumor angiogenesis plays a critical role in tumor progression and metastasis [128]. CAFs have been found to facilitate tumor angiogenesis by secreting a variety of angiogenic factors, such as vascular endothelial growth factor (VEGF) and FGF2 [129, 130]. Interestingly, some studies have suggested that miRNAs, which can regulate the secretion of VEGF and even control the function of endothelial cells, may also be important regulators of tumor angiogenesis [131, 132]. Thus, some researchers have begun to explore whether miRNAs contribute to CAF-mediated angiogenesis. High vascularization is one of the main features of melanoma. Exosomal miR-155 derived from melanoma cells inhibits the expression of suppressor of cytokine signaling 1 (SOCS1) by targeting its $3^{\prime}$ UTR and activates the JAK2/STAT3 signaling pathway. This pathway upregulates the expression of VEGFa, FGF2 and MMP9 in fibroblasts and then influences the angiogenic effect of CAFs [133]. A recent study has 
shown that exosomal miR-210 derived from lung cancer cells acts as a proangiogenic factor in CAFs also by modulating the JAK2/STAT3 pathway [134]. In addition, hypoxia-induced overexpression of miR-210 can induce the conversion of NFs into CAFs, further affecting the recruitment of endothelial progenitor cells and the capillary formation by human umbilical vein endothelial cells (HUVECs) [105]. In breast cancer, a decreased level of exosomal miR-205 induces activation of the target gene YAP1 in CAFs, which promotes HUVEC tube formation and sprouting [135]. The expression of IL-11 and IL-15 is specifically enhanced by YAP1, while their release by CAFs activates STAT3 signaling in HUVECs, thus promoting angiogenesis. The current studies indicate that miRNAs from CAFs affect tumor angiogenesis mainly through STAT3 signaling, and further exploration is required to determine whether other pathways also contribute to this process.

\section{Invasion, migration and metastasis}

CAFs promote tumor invasion, migration and metastasis in many ways, and the regulation of ECM remodeling is one of the important mechanisms [136]. A recent study showed that a matrix-dependent mechano-sensitization of EGF signaling in cancer cells can drive the collective invasion of squamous cell carcinoma (SCC) cells [137]. SCC cells activate EGFR under the condition of tumor stiffness and lead to $\mathrm{Ca}^{2+}$-dependent regulation of $\mathrm{Cdc} 42$ small GTPase activity, which results in MLC2 phosphorylation. Then the MLC kinase regulates actomyosin-dependent ECM remodeling induced by CAFs and ultimately promotes the invasion of SCC $[57,136,137]$. MiRNA dysregulation in CAFs can also mediate tumor cell invasion and metastasis by regulating ECM remodeling. Downregulation of miR-200s in CAFs increases the expression of Fli-1 and TCF12, which facilitates ECM remodeling and the production of parallel pattern-oriented ECM fibers by CAFs, thus accelerating the invasion and metastasis of tumor cells [138]. Mechanistically, inhibition of Fli-1 or TCF12 in CAFs counteracts the contractile activity induced by CAFs, but overexpression of Fli-1 or TCF12 in NFs increases the contractile activity of these NFs. In another study, a combined regression model was used to identify the subgroup-specific miRNAs and functional gene sets in colorectal cancer, and that the results indicated that some miRNAs can regulate ECM target genes [139]. Further studies showed that the high expression of miR-192, miR-17 and miR-200c in fibroblasts can regulate ECM target gene expression at the protein level, thus regulating ECM remodeling. Finally, a coculture experiment confirmed that the high expression of miR-192, miR-17 and miR-200c in colon CAFs decreases the invasive ability of colorectal cancer cells [139]. In addition, PAIs are important molecules in tumor invasion and metastasis. The expression of PAI-1 in CAFs is increased by the miR-200b, c/NF- $k B$ axis, which induces polarity changes, such as a decrease in E-cadherin and an increase in Vimentin, in cancer cells, thus enhancing their invasive ability [113]. Similarly, through coculture experiments and wound healing assays, it has been proven that the miR-15a/PAI-2 axis promotes the migration of cholangiocarcinoma cells [140]. Furthermore, silencing of miR-148a in CAFs promotes the migration of endometrial cancer cells by targeting $W n t 10 B$ to activate the Wnt/ $\beta$-catenin pathway [141]. As shown in Table 2, other miRNAs in CAFs are also involved in tumor invasion, migration and metastasis in vitro or in vivo, as confirmed by coculture or xenograft experiments.

EMT, which can enhance the initiating and metastatic potential of cancer cells, is an important process affecting tumor metastasis [142]. Downregulation of miR-214 in gastric CAFs can promote EMT of gastric cancer cells, which is characterized by increased expression of E-cadherin and decreased expression of N-cadherin, Vimentin and Snail. This promotive effect may be achieved through the direct targeting of FGF9 by miR-214 and eventually lead to the migration and invasion of gastric cancer cells [143]. Importantly, CAFs can also enhance the EMT and stem-like characteristics of gastric cancer cells through the miR-149/IL-6 axis [87]. Gastric cancer cells induce the activation of the COX2/ PGE2 signaling pathway and enhance the production of PGE2, which leads to epigenetic silencing of miR-149 in CAFs, thus ultimately facilitating tumor progression. CAF-derived exosomal miRNAs are also important for EMT in cancer cells. A study in a xenograft model proved that exosomal miR-181d-5p derived from CAFs induces EMT in breast cancer by regulating CDX2 and HOXA5 in vivo [144]. In endometrial cancer, exosomal miR148b derived from CAFs inhibits EMT and invasion of cancer cells by directly targeting DNMT1, thus regulating cancer metastasis in vitro and in vivo [145]. In lung cancer, CAF-derived exosomal miR-210 can promote EMT by targeting UPF1 to activate the PTEN/PI3K/AKT signaling pathway [146]. Additionally, loss of exosomal miR-34a-5p activates the AKT/GSK-3 $/ \beta$-catenin/Snail signaling pathway by directly targeting $A X L$, ultimately accelerating EMT and invasion of cancer cells [147].

CAF-derived exosomal miRNAs can also directly regulate tumor invasion and metastasis by targeting related genes. A recent study demonstrated that the regulation of miR-16 and miR-148a in CAF-derived exosomes by FAK signaling contributes to alterations in the ability of CAFs to affect the activity and metastasis of breast cancer cells [148]. Additionally, CAF-derived exosomes with decreased levels of miR-3613-3p lead to suppression 
of proliferation and metastasis via targeting of SOCS2 [149]. In gastric cancer, an increase in MMP11 in CAF exosomes induces the migration and metastasis of cancer cells, while CAF-derived exosomal miR-139 negatively regulates the level of MMP11 [118]. As summarized in Table 2, other exosomal miRNAs, such as miR-1228 in osteosarcoma [150] and miR-21 in colorectal cancer [151], can also participate in the regulation of tumor metastasis by targeting different genes.

\section{Therapeutic resistance}

Despite recent progress in chemotherapy, molecular therapy and immunotherapy, many patients do not benefit from these treatment modalities [152]. Accumulating studies have proven that CAFs are closely related to therapeutic resistance and poor prognosis [8]. Therapeutic resistance of tumors can be induced by CAFs via many mechanisms, including the secretion of paracrine signaling mediators, such as cytokines and exosomes; prevention of drug delivery; reprogramming of metabolism; and regulation of signaling pathways [7, 34, 122, 153]. MiRNAs also play an indispensable role in these processes.

The effect of miRNA dysregulation in CAFs on tumor drug resistance has been widely studied. As early as 2013, Bullock et al. found that coculture with fibroblasts overexpressing miR-21 can protect colorectal cancer cells from apoptosis induced by oxaliplatin and increase the proliferative ability of these cells [83]. In addition, Zhang et al. proved through animal experiments that upregulation of miR-21 in CAFs can promote desmoplasia and increase gemcitabine resistance in PDAC [154]. In lung cancer, the expression of stromal cell-derived factor 1 (SDF-1) in CAFs is negatively regulated by miR-1. SDF-1 promotes the proliferation and cisplatin resistance of lung cancer cells through CXCR4-modulated NF-kB and Bcl-xL signaling pathways [155]. In a study on esophageal cancer, coculture with miR-27a/b-transfected NFs was found to reduce the sensitivity of cancer cells to cisplatin [156].

The role of exosomal miRNAs in CAF-mediated therapeutic resistance has been continuously reported in recent years. In gastric cancer, cisplatin and paclitaxel accelerate the secretion of exosomal miR-522 from CAFs by activating the USP7/hnRNPA1 axis, which results in inhibition of ALOX15. Downregulation of ALOX15 reduces the accumulation of lipid-ROS in cancer cells, which ultimately leads to acquired drug resistance [127]. In colorectal cancer, exosomal miR-92a-3p secreted from CAFs activates the Wnt/ $\beta$-catenin signaling pathway and inhibits mitochondrial apoptosis through direct inhibition of FBXW7 and MOAP1, resulting in 5-fluorouracil/ oxaliplatin resistance [122]. Qin et al. reported that exosomal miR-196a enhances the proliferation and cisplatin resistance of head and neck cancer cells by promoting G1/S cell cycle transition and inhibiting apoptosis via targeting CDKN1B and ING5 [157]. In addition, this study reconfirmed the importance of hnRNPA1 in mediating the formation of CAF-derived exosomes. As shown in Table 2, CAF-derived miR-21 and miR-98-5p in ovarian cancer and miR-146a and miR-106b in pancreatic cancer target different molecules but consistently mediate the process of tumor drug resistance [119, 158-160].

\section{MiRNAs in CAFs and cancer immunosuppression}

The emergence of immunotherapy represents a major breakthrough in cancer treatment, but most patients show resistance to these therapies. Growing evidence has shown that the TME is one of the key determinants of the tumor immune response, and CAFs are closely associated with the efficacy of immunotherapy [161]. CAFs directly interact with immune cells by secreting growth factors, cytokines and chemokines, thus mediating and regulating the infiltration of immune cells [162]. In addition, CAFs can also create a physical immune barrier through ECM remodeling to exert immunomodulatory effects [163]. Although considerable evidence confirms that CAFs mainly play an immunosuppressive role, recent studies have demonstrated that some subpopulations of CAFs may also be related to the activation of the tumor immune response and to a better prognosis [52, 164]. Studies on the role of miRNAs in CAFs in cancer immunomodulation are also ongoing. A recent study found that in lung cancer tissues, the high expression of IncRNA PCAT-1 is related to the induction and infiltration of CAFs, which may be achieved via the immunosuppressive miR-182/miR-217 signaling [165]. Concurrently, the high expression of PCAT-1 is closely associated with the immunosuppression of lung cancer. Although further verification is still needed, this study suggests that CAFs may mediate lung cancer immunosuppression through ncRNAs. As mentioned earlier, Givel et al. grouped CAFs into four subpopulations [56]. Under the action of miR141 and miR-200a, members of the miR-200 family, the expression of CXCL12 $\beta$ was downregulated in CAF-S4 fibroblasts and upregulated in CAF-S1 fibroblasts. CAFs with high expression of CXCL12 $\beta$ improve the survival in $\mathrm{CD}_{25}{ }^{+} \mathrm{FOXP}^{+}{ }^{+} \mathrm{T}$ lymphocytes and result in immunosuppression. Additionally, CAF-S1 fibroblasts can also increase the content of $\mathrm{CD} 25^{+} \mathrm{Foxp} 3^{+} \mathrm{T}$ lymphocytes, which is mediated by the high expression of $\mathrm{B} 7-\mathrm{H} 3$, CD73 and IL6 [56].

\section{MiRNAs in CAFs as biomarkers for cancer prognosis}

The prognosis of cancer patients has always been the focus of attention. The discovery of effective prognostic biomarkers will undoubtedly contribute greatly to the 
treatment and management of cancer patients. Therefore, in addition to investigating the role of miRNAs in the interaction between CAFs and tumor cells, many studies have begun to consider the potential of miRNAs in CAFs to be prognostic biomarkers (Table 3). Interestingly, Lee et al. found that in colorectal cancer patients with distant metastasis, low expression of miR-21 in stromal fibroblasts in the periphery of the primary tumor was significantly associated with poorer overall survival (OS) [166], a conclusion quite different from those of Kunita et al. [167] and Kadera et al. [168]. To some extent, this discrepancy indicates that the prognostic value of miRNAs in CAFs needs further verification, and this need has launched a new direction for the further study of miR-21. In addition, as shown in Table 3, in some studies of CAF exosomes, researchers have reported the prognostic value of serum or plasma exosomal miRNAs [96, 157]. However, more studies are needed to prove whether the effects of these miRNAs are consistent with those of miRNAs in CAF-derived exosomes.

\section{Potential therapeutic approaches for targeting miRNAs and exosomes \\ Targeting miRNAs}

Because miRNAs can play either a promotive or suppressive role in tumors, there are two main therapeutic approaches targeting miRNAs: reducing the expression of miRNAs that act as oncogenes (onco-miRNAs) and restoring the expression of miRNAs that act as tumor suppressors. The expression or function of onco-miRNAs can be inhibited by using single-stranded antisense RNAs, small molecule antagonists or miRNA sponges, while the expression or function of tumor suppressor
miRNAs can be enhanced via double-stranded miRNA mimics [22]. To date, relatively few clinical trials of miRNA-targeted therapy in tumors have been conducted, and these trials have focused primarily on the following targets: miR-34a (NCT01829971, NCT02862145), miR155 (NCT02580552, NCT03713320, NCT03837457) and miR-16 (NCT02369198). Although some trials have failed and most studies are still in the early stage, these studies still show the prospects of miRNA-targeted therapy, as well as some experiences worthy of consideration. In studies of miRNAs in CAFs, some scholars have also tried to study their potential therapeutic targets and methods and have made interesting findings. For example, Ren et al. reported that treatment of CAFs with AC1MMYR2, a small molecule inhibitor of miR-21, can suppress tumor growth and metastasis and improve chemosensitivity [169]. However, in practical applications, miRNA-targeted therapies do not simply promote or inhibit the expression of miRNAs. We previously mentioned that one miRNA can regulate the expression of multiple genes; thus, when a drug acts on a target miRNA, off-target effects inevitably occur. Hence, identifying the best miRNA targets in different kinds of tumors is highly challenging. Lai et al. proposed the use of cooperating miRNAs to treat tumors, aiming to minimize toxicity and reduce off-target effects, but high-quality clinical trials are needed to confirm the feasibility of this strategy [170]. In addition, because RNA molecules are unstable, it is necessary to modify the molecules or develop an effective delivery system for miRNA-targeted therapy; moreover, the safety of these methods should be considered [171]. Indeed, one clinical trial (NCT01829971) was terminated due to immune-related

Table 3 MicroRNAs in cancer-associated fibroblasts as biomarkers for cancer prognosis

\begin{tabular}{|c|c|c|c|c|c|c|c|}
\hline Cancer type & No. of samples & ncRNA & $\begin{array}{l}\text { Dysregulation } \\
\text { or exomosal }\end{array}$ & Method & Expression* & Result in & References \\
\hline Colorectal cancer & 170 & miR-21 & Dysregulation & $\mathrm{ISH}$ & $\downarrow$ & Poorer OS & {$[166]$} \\
\hline Gastric cancer & 120 & miR-106b & Dysregulation & $\mathrm{ISH}$ & $\uparrow$ & Poorer OS & {$[208]$} \\
\hline Gastric cancer & 68 & miR-143 & Dysregulation & ISH and qRT-PCR & $\uparrow$ & Higher CSM & {$[209]$} \\
\hline Gastric cancer & 71 & miR-145 & Dysregulation & qRT-PCR & $\uparrow$ & Higher CSM & {$[210]$} \\
\hline Head and neck cancer & 74 & miR-196a & Exomosal & qRT-PCR & $\uparrow$ & Poorer OS & {$[157]$} \\
\hline Hepatocellular carcinoma & 85 & miR-21 & Exomosal & qRT-PCR & $\uparrow$ & Poorer OS & {$[96]$} \\
\hline Lung cancer & 89 & miR-21 & Dysregulation & $\mathrm{ISH}$ & $\uparrow$ & Poorer OS & {$[167]$} \\
\hline Lung cancer & 134 & miR-200a & Dysregulation & ISH & $\downarrow$ & Poorer OS & {$[211]$} \\
\hline Pancreatic cancer & 153 & miR-21 & Dysregulation & $\mathrm{ISH}$ & $\uparrow$ & Poorer OS & {$[168]$} \\
\hline $\begin{array}{l}\text { Oral squamous } \\
\text { cell carcinoma }\end{array}$ & 140 & IncRNA FLJ22447 & Dysregulation & qRT-PCR & $\uparrow$ & Poorer OS & {$[188]$} \\
\hline Ovarian cancer & 62 & 10 IncRNAs & Dysregulation & - & - & Poorer OS & [199] \\
\hline
\end{tabular}

OS, overall survival; CSM, cancer-specific mortality

*Refers to the expression level of the poor prognosis group in the case-control study 
toxicity in several patients. Therefore, miRNA-targeted therapy needs further exploration.

\section{Targeting exosomes}

Tumor-promoting ncRNAs loaded in exosomes are vital for tumor progression after being taken up by tumor cells or stromal cells. Therefore, many studies are devoted to blocking the effect of exosomes from many directions, such as suppressing their formation, release and uptake, to treat cancer [172]. Marleau et al. developed a system called adaptive dialysis-like affinity platform technology that aims to treat tumors by capturing and removing tumor-related exosomes from the circulation [173]. On the other hand, as mentioned earlier, an effective and safe delivery system is required in RNA-targeted therapy, and exosomes meet this need. Currently, a key direction in exosome research is isolating exosomes, combining them with ncRNAs that act as tumor suppressors, and then effectively transferring them to tumor tissues to obtain therapeutic effects. This direction is also being pursued in research on CAFs. Wang et al. found that the expression of miR-335-5p was downregulated in HCC cells and CAFs, while the invasive ability of HCC cells in an in vitro model was decreased after treatment with exosomal miR-335-5p. Further studies using animal models have shown that exosomal miR-335-5p can inhibit tumor growth in vivo by reducing proliferation and increasing apoptosis [174]. Another study by the same team also demonstrated that exogenous exosomal miR-195 can inhibit the growth of cholangiocarcinoma in vivo and prolong survival [175]. These studies indicate the potential prospects of exosome replacement therapy.

\section{LncRNAs in CAFs}

\section{Biosynthesis and mechanisms of IncRNAs}

LncRNAs are a class of RNA molecules with sequences longer than $200 \mathrm{nt}$ that includes mainly long intergenic noncoding RNAs (lincRNAs) and natural antisense transcripts (NATs) of protein-coding genes [176, 177]. Like mRNAs, most lncRNAs are transcribed by RNA polymerase II and have a $5^{\prime} \mathrm{m}^{7} \mathrm{G}$ cap and $3^{\prime}$ poly(A) tail. However, there are other differences; for example, lncRNAs have cis-regulation ability but lack translated ORFs and coding ability [178]. Importantly, the overall family of lncRNAs also includes unconventional lncRNAs derived from primary RNA polymerase II-derived transcripts, and the $3^{\prime}$ ends of these lncRNAs are processed via a unique mechanism. For instance, two types of unconventional lncRNAs, snoRNA-ended lncRNAs (snolncRNAs) and 5'-snoRNA-ended and 3'-polyadenylated lncRNAs (SPAs), enhance the structural stability of RNA molecules by capping one or both of their ends via small nucleolar ribonucleoproteins (snoRNPs) [179]. Due to the operational definition of lncRNAs, some researchers divided them into various subsets according to different characteristics, as reviewed in Ref.[180].

LncRNAs have more diverse functions than miRNAs, and these functions cannot be simply inferred from their sequence or structure. Chromatin modification is an important function of lncRNAs. LncRNAs can interact with chromatin-modifying complexes and mediate epigenetic changes by recruiting these complexes to specific genomic loci [181]. Another function of IncRNAs is transcriptional regulation. LncRNAs can transcriptionally regulate the expression of genes in cis or target distant transcriptional activators or inhibitors, a process called trans-action [182]. In addition, lncRNAs can regulate the activities of RNA polymerase II and transcription factors through different mechanisms [183]. LncRNAs have also been found to bind directly to DNA to alter gene expression via the formation of R-loops or RNA-DNA triplex structures [184, 185]. However, lncRNAs also play a pivotal role in posttranscriptional regulation. Recently, many lncRNAs have been identified to regulate gene expression at the posttranscriptional level by changing the function and integrity of nuclear bodies [14]. Additionally, lncRNAs may mediate specific interactions associated with multiple steps of posttranscriptional mRNA processing, such as splicing, transport and degradation. Interestingly, some nuclear-localized lncRNAs have been found to be related to ribosomes, which proves that lncRNAs may be involved in translational regulation [186].

\section{LncRNAs in the formation and activation of CAFs}

LncRNAs contribute to the formation and activation of CAFs. A new pan-cancer integration strategy was applied to classify lncRNAs into 16 modules according to different functional signatures. Twelve lncRNAs involved in one of the modules were found to be closely related to the formation of CAFs. The authors carried out siRNA knockdown experiments and observed that the transformation of NFs to CAFs was decreased, confirming this correlation [187]. In another study, a lncRNA significantly upregulated in CAFs was identified from oral squamous cell carcinoma (OSCC) by RNA sequencing; this lncRNA was found to promote the transformation of NFs to CAFs and affect the proliferation of cancer cells by increasing the IL-33 level [188]. Furthermore, Hu et al. found that the IncRNA Gm26809 in exosomes secreted from melanoma cells was taken up by NFs and reprogrammed them into CAFs, thus facilitating the proliferation and migration of melanoma cells [189].

\section{LncRNAs in the effect of CAFs on cancer cells}

With the continuous emphasis on the role of lncRNAs in the TME, researchers have begun to consider the 
function of lncRNAs in CAFs, as well as the effects of lncRNA dysregulation and exosomal lncRNAs derived from CAFs on cancer cells (Fig. 3) [190, 191].

\section{Metastasis and metabolic reprogramming}

The effect of lncRNAs in CAFs on cancer metastasis has been verified in many studies. Vafaee et al. analyzed the RNA expression of CAFs and NFs in ovarian cancer and identified 39 differentially expressed lncRNAs, some of which can predict cancer metastasis [192]. A recent study demonstrated that lnc003875 induces cancer metastasis by promoting angiogenesis [193]. In placental site trophoblastic tumors, lnc003875 upregulates the expression of early growth response 1 (EGR1), which promotes angiopoietin-1 (Ang-1) secretion by CAFs to enhance angiogenesis. As mentioned in the previous section, EMT is a crucial mechanism in cancer metastasis. The lncRNA TIRY can decrease the level of exosomal miR-14 derived from CAFs in OSCC as a miRNA sponge. MiR-14 inhibits the Wnt/ $\beta$-catenin signaling pathway by targeting Wnt $3 A$, thus inhibiting EMT of cancer cells.
However, the lncRNA TIRY activates this pathway and finally induces the invasion and metastasis of OSCC cells [194]. Importantly, in ovarian cancer, linc00092 maintains the local supportive function of CAFs by binding to 6-phosphofructo-2-kinase/fructose-2,6-biphosphatase 2 (PFKFB2) to promote glycolysis in cancer cells, thus contributing to cancer metastasis [195]. Another study revealed that exosomal lncRNA SNHG3 secreted from CAFs acts as a miRNA sponge to decrease the level of miR-330-5p in cancer cells, which in turn increases the expression of pyruvate kinase M1/M2 (PKM), one of the main rate-limiting enzymes in glycolysis [196]. These results indicate that the substantial effect of lncRNAs on metabolic regulation is also reflected in the crosstalk between CAFs and cancer cells.

\section{Chemoresistance}

LncRNAs in CAFs also play an important role in chemoresistance. Enrichment of the lncRNA H19 in exosomes secreted from CAFs can promote the stemness of colorectal CSCs and the oxaliplatin resistance of colorectal

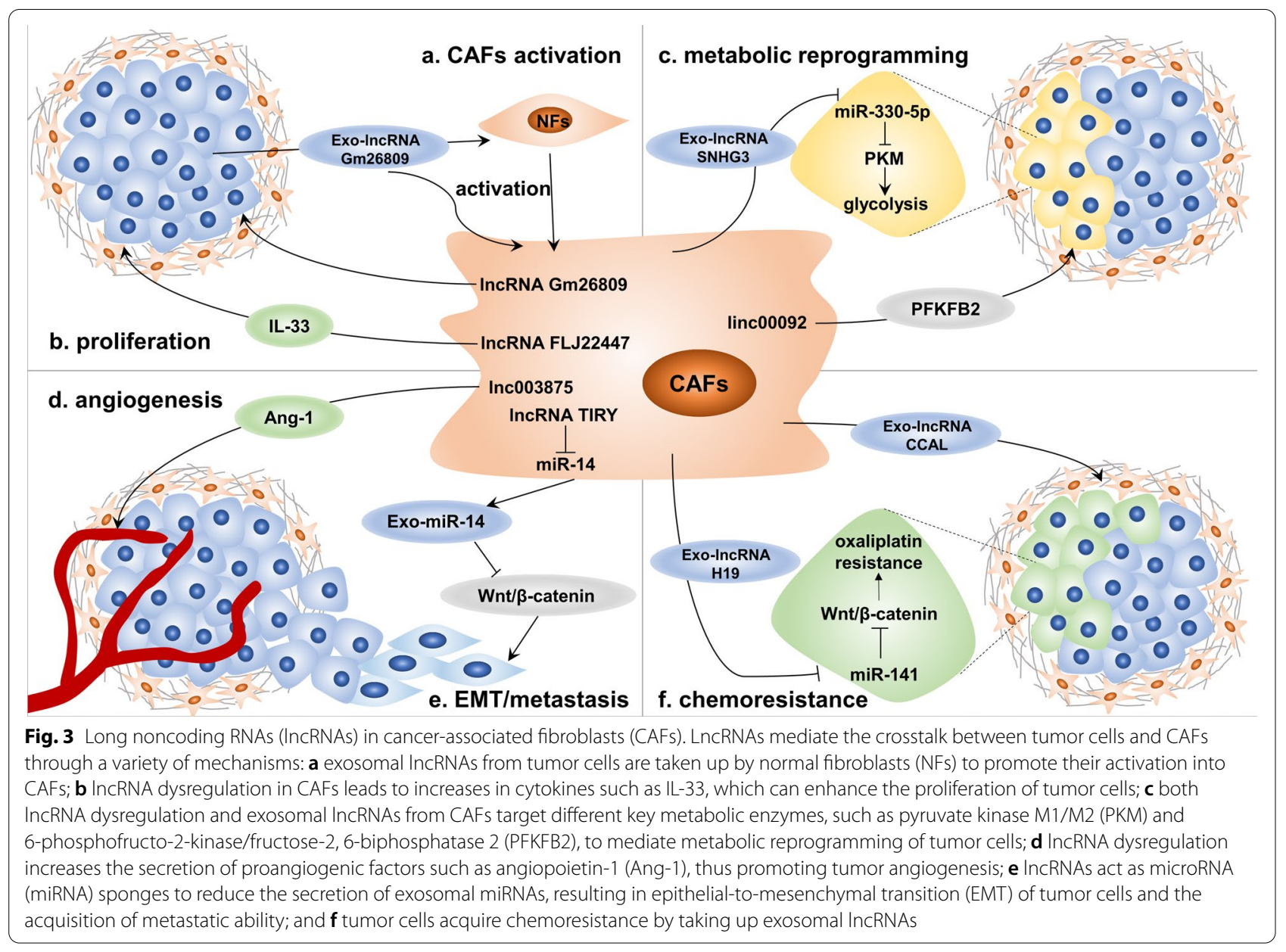


cancer cells in vitro and in vivo [197]. Interestingly, $\mathrm{H} 19$ can also act as a sponge of miR-141 to regulate the expression of $\beta$-catenin, and the $\mathrm{Wnt} / \beta$-catenin pathway is essential for the maintenance of CSCs and chemoresistance of cancer cells. Similarly, another study confirmed that exosomal colorectal cancer-associated lncRNA (CCAL) derived from CAFs upregulates the expression of $\beta$-catenin by interacting with the mRNAstabilizing protein $\mathrm{HuR}$, which promotes the oxaliplatin resistance of colorectal cancer cells [198].

\section{LncRNAs in CAFs as biomarkers for cancer prognosis}

A recent study illustrated the prognostic value of lncRNAs in CAFs. This study identified 10 differentially expressed lncRNAs associated with poorer overall survival in ovarian cancer CAFs [199]. In particular, 9 of these lncRNAs were differentially expressed only in CAFs, not in tumor cells, which reveals the vital functions of lncRNAs in CAFs. Importantly, the high expression of MIR155HG, one of the identified lncRNAs, is associated with higher immune cell infiltration, which may be a reason for its impact on patient prognosis. In addition, as shown in Table 3, the lncRNA FLJ22447 can also be used as a prognostic factor in OSCC [188].

\section{Potential therapeutic approaches for targeting IncRNAs}

LncRNAs are transcripts similar to mRNAs; thus, many molecules that act on mRNAs, such as antisense oligonucleotides (ASOs), siRNAs, small molecule antagonists, and ribozymes, can also be used to target lncRNAs [200]. ASOs are chemically modified, synthetic singlestranded oligonucleotides that can bind to complementary sequences in RNA molecules, resulting in RNase $\mathrm{H}$-dependent degradation of the target lncRNAs [201]. RNA interference is another important means of targeting lncRNAs. SiRNAs bind to lncRNAs and induce the formation and activation of the RISC, which finally leads to degradation of the lncRNAs. Importantly, lncRNAs can exert a marked effect by loading into exosomes. Therefore, targeting exosomes (which were introduced earlier) is also a potential therapeutic approach. Although there are many strategies for lncRNA-targeted therapy, because studies on lncRNAs in CAFs are still in the preliminary stage, we need to further understand their function and mechanism to develop more effective treatments.

\section{Conclusions}

The importance of the TME, as a key regulator of tumor progression, has received increasing attention. A deeper understanding of CAFs, a kind of stromal cell that is the main component of the TME, is very helpful for us to further clarify the mechanisms by which the TME contributes to tumor progression. CAFs are a heterogeneous population of cells of multiple origins that mainly promote the development of tumors. However, some recent studies have shown that they can also have tumorsuppressive effects. Although some studies have reported that gene mutations are present in CAFs, such mutations are generally believed to be uncommon. Therefore, the phenotypic and functional changes in CAFs are regulated mainly by other factors, among which ncRNAs play a crucial role. As reviewed herein, miRNAs participate in the formation and activation of CAFs and modulate their metabolic reprogramming, which is one of the important characteristics that distinguishes CAFs from NFs and is a prerequisite for the role of CAFs. This process can be accomplished through miRNA dysregulation in CAFs or mediated by exosomal miRNAs secreted from tumor cells. Subsequently, through miRNAs, activated CAFs can regulate numerous biological functions in tumor cells, including proliferation, stemness, metabolism, angiogenesis, invasion, metastasis and the acquisition of therapeutic resistance. These regulatory effects can be exerted through miRNA dysregulation in CAFs, which leads to the transformation of the matrix-regulatory function of CAFs and the secretion of related molecules to regulate tumor cells. Similarly, through secreted exosomes, exosomal miRNAs can be transferred to tumor cells and act directly on the corresponding targets to regulate a series of biological characteristics. It can be seen that miRNAs are involved in almost all aspects of communication between CAFs and tumor cells. Moreover, studies on lncRNAs in CAFs are being carried out gradually and have shown the expected results, which reveal that lncRNAs also contribute to tumor progression via many mechanisms. Interestingly, some studies have shown that lncRNAs act as miRNA sponges to regulate the level of miRNAs, linking the study of lncRNAs with the study of miRNAs. However, most of the studies mentioned in our review have focused on the mechanism of a single signaling pathway mediated by a single ncRNA, and further research on the complex regulatory networks in the TME is lacking.Therefore, the conclusions of our studies may be one-sided and address only part of a large and complex network. As research on ncRNAs intensifies, we should conduct more in-depth studies on the regulatory networks mediated by ncRNAs to identify both the overall function of a single ncRNA and the synergistic functions of multiple ncRNAs and to validate the driving factors and causal relationships. This knowledge will help us to identify the optimal single or multiple ncRNA targets in order to design more effective and safer treatments. Last but not least, the in-depth study of ncRNAs in CAFs can enable us to further understand the nature and biological characteristics of CAFs and may facilitate 


\section{the identification of additional treatments targeting CAFs, rather than just treatments targeting ncRNAs.}

\begin{abstract}
Abbreviations
3' UTR: 3' Untranslated region; ALOX15: Arachidonate lipoxygenase 15; Ang-1: Angiopoietin-1; apCAFs: Antigen-presenting CAFs; ASOs: Antisense oligonucleotides; BCL2: B-cell lymphoma 2; BMP: Bone morphogenetic protein; CAFs: Cancer-associated fibroblasts; CCAL: Colorectal cancer-associated IncRNA; CDK2: Cyclin-dependent kinase 2; circRNAs: Circular RNAs; CSCs: Cancer stem cells; CXCL: C-X-C motif chemokine ligand; CXCR: C-X-C motif chemokine receptor; DGCR8: DiGeorge critical region 8; ECM: Extracellular matrix; EGF: Epidermal growth factor; EGR1: Early growth response 1; EMT: Epithelial-tomesenchymal transition; EndoMT: Endothelial-to-mesenchymal transition; FAP: Fibroblast activation protein; FGF2: Fibroblast growth factor 2; HCC: Hepatocellular carcinoma; HSCs: Hepatic stellate cells; HUVECs: Human umbilical vein endothelial cells; iCAFs: Inflammatory CAFs; IL: Interleukin; lincRNAs: Long intergenic noncoding RNAs; IncRNAs: Long noncoding RNAs; MDSCs: Myeloidderived suppressor cells; miRNAs: MicroRNAs; MMP: Matrix metalloproteinase; MSCs: Mesenchymal stem cells; MTOC: Microtubule-organizing center; myCAFs: Myofibroblastic CAFs; NATs: Natural antisense transcripts; ncRNAs: Noncoding RNAs; NFs: Normal fibroblasts; ORFs: Open reading frames; OS: Overall survival; OSCC: Oral squamous cell carcinoma; PAls: Plasminogen activator inhibitors; PAR-4: Protease-activated receptor 4; PDAC: Pancreatic ductal adenocarcinoma; PDGF: Platelet-derived growth factor; PEDF: Pigment epithelium-derived factor; PFKFB2: 6-Phosphofructo-2-kinase/fructose2,6-biphosphatase 2; piRNAs: Piwi-interacting RNAs; PKM: Pyruvate kinase M1/M2; PSCs: Pancreatic stellate cells; RBPs: RNA-binding proteins; RISC: RNAinduced silencing complex; ROS: Reactive oxygen species; SCC: Squamous cell carcinoma; SDF-1: Stromal cell-derived factor 1; SHH: Sonic hedgehog; siRNAs: Small interfering RNAs; sncRNAs: Small noncoding RNAs; sno-IncRNAs: SnoRNA-ended IncRNAs; snoRNPs: SnoRNA-protein complexes; SOCS1: Suppressor of cytokine signaling 1; SPAs: $5^{\prime}$-SnoRNA-ended and $3^{\prime}$-polyadenylated IncRNAs; TCA: Tricarboxylic acid; TGF- $\beta$ : Transforming growth factor- $\beta$; TME: Tumor microenvironment; VEGF: Vascular endothelial growth factor; $\alpha$-SMA: a-Smooth muscle actin.
\end{abstract}

\section{Acknowledgements}

Not applicable.

\section{Authors' contributions}

ZLF, JX and BZ collected the related studies and drafted the manuscript. WW, $J \mathrm{~L}, \mathrm{CL}$ and $\mathrm{JH}$ participated in the design of the review. SS, XJY and QCM initiated the study and revised the manuscript. All authors read and approved the final manuscript.

\section{Funding}

This study was jointly funded by the National Natural Science Foundation of China (No. 81802352, 81772555 and 81902428), the National Science Foundation for Distinguished Young Scholars of China (No. 81625016), the Shanghai Sailing Program (No. 19YF1409400 and 20YF1409000), the Shanghai RisingStar Program (No. 20QA1402100), the Shanghai Anticancer Association Young Eagle Program (No. SACA-CY19A06), the Clinical and Scientific Innovation Project of Shanghai Hospital Development Center (No. SHDC12018109 and SHDC12019109) and the Scientific Innovation Project of Shanghai Education Committee (No. 2019-01-07-00-07-E00057).

\section{Availability of data and materials}

Not applicable.

\section{Ethics approval and consent to participate} Not applicable.

\section{Consent for publication}

Not applicable.

\section{Competing interests}

The authors declare that they have no competing interests.

\section{Author details}

${ }^{1}$ Department of Pancreatic Surgery, Fudan University Shanghai Cancer Center, No. 270 Dong'An Road, Shanghai 200032, China. ${ }^{2}$ Department of Oncology, Shanghai Medical College, Fudan University, Shanghai 200032, China. ${ }^{3}$ Shanghai Pancreatic Cancer Institute, Shanghai 200032, China. ${ }^{4}$ Pancreatic Cancer Institute, Fudan University, Shanghai 200032, China.

Received: 2 October 2020 Accepted: 2 November 2020

Published online: 19 November 2020

\section{References}

1. Hinshaw DC, Shevde LA. The tumor microenvironment innately modulates cancer progression. Cancer Res. 2019;79:4557-66.

2. Junttila MR, de Sauvage FJ. Influence of tumour micro-environment heterogeneity on therapeutic response. Nature. 2013;501:346-54.

3. Giraldo NA, Sanchez-Salas R, Peske JD, Vano Y, Becht E, Petitprez F, et al. The clinical role of the TME in solid cancer. Br J Cancer. 2019;120:45-53.

4. Hanahan D, Coussens LM. Accessories to the crime: functions of cells recruited to the tumor microenvironment. Cancer Cell. 2012;21:309-22.

5. Vennin C, Murphy KJ, Morton JP, Cox TR, Pajic M, Timpson P. Reshaping the tumor stroma for treatment of pancreatic cancer. Gastroenterology. 2018;154:820-38

6. Kalluri R. The biology and function of fibroblasts in cancer. Nat Rev Cancer. 2016;16:582-98.

7. Chen X, Song E. Turning foes to friends: targeting cancer-associated fibroblasts. Nat Rev Drug Discov. 2019;18:99-115.

8. Ishii G, Ochiai A, Neri S. Phenotypic and functional heterogeneity of cancer-associated fibroblast within the tumor microenvironment. Adv Drug Deliv Rev. 2016;99:186-96.

9. Ohlund D, Handly-Santana A, Biffi G, Elyada E, Almeida AS, Ponz-Sarvise $M$, et al. Distinct populations of inflammatory fibroblasts and myofibroblasts in pancreatic cancer. J Exp Med. 2017;214:579-96.

10. Chan JS, Tan MJ, Sng MK, Teo Z, Phua T, Choo CC, et al. Cancer-associated fibroblasts enact field cancerization by promoting extratumoral oxidative stress. Cell Death Dis. 2017;8:e2562.

11. Martinez-Outschoorn UE, Lisanti MP, Sotgia F. Catabolic cancer-associated fibroblasts transfer energy and biomass to anabolic cancer cells, fueling tumor growth. Semin Cancer Biol. 2014;25:47-60.

12. Kobayashi H, Enomoto A, Woods SL, Burt AD, Takahashi M, Worthley DL. Cancer-associated fibroblasts in gastrointestinal cancer. Nat Rev Gastroenterol Hepatol. 2019:16:282-95.

13. Yates LA, Norbury CJ, Gilbert RJ. The long and short of microRNA. Cell. 2013;153:516-9.

14. Yao RW, Wang Y, Chen LL. Cellular functions of long noncoding RNAs. Nat Cell Biol. 2019;21:542-51.

15. Memczak S, Jens M, Elefsinioti A, Torti F, Krueger J, Rybak A, et al. Circular RNAs are a large class of animal RNAs with regulatory potency. Nature. 2013:495:333-8.

16. Lei M, Zheng G, Ning Q, Zheng J, Dong D. Translation and functional roles of circular RNAs in human cancer. Mol Cancer. 2020;19:30.

17. Tüfekci KU, Oner MG, Meuwissen RL, Genç S. The role of microRNAs in human diseases. Methods Mol Biol. 2014;1107:33-50.

18. Uchida S, Dimmeler S. Long noncoding RNAs in cardiovascular diseases. Circ Res. 2015;116:737-50.

19. Schmitt AM, Chang HY. Long noncoding RNAs in cancer pathways. Cancer Cell. 2016;29:452-63.

20. Haddad G, Lorenzen JM. Biogenesis and function of circular RNAs in health and in disease. Front Pharmacol. 2019;10:428.

21. Rupaimoole R, Calin GA, Lopez-Berestein G, Sood AK. miRNA deregulation in cancer cells and the tumor microenvironment. Cancer Discov. 2016;6:235-46.

22. Slack FJ, Chinnaiyan AM. The role of non-coding RNAs in oncology. Cell. 2019:179:1033-55.

23. Zhou R, Wu Y, Wang W, Su W, Liu Y, Wang Y, et al. Circular RNAs (circRNAs) in cancer. Cancer Lett. 2018:425:134-42.

24. Lohr M, Schmidt C, Ringel J, Kluth M, Muller P, Nizze H, et al. Transforming growth factor-beta1 induces desmoplasia in an experimental model of human pancreatic carcinoma. Cancer Res. 2001;61:550-5. 
25. Erez N, Truitt M, Olson P, Arron ST, Hanahan D. Cancer-associated fibroblasts are activated in incipient neoplasia to orchestrate tumorpromoting inflammation in an NF-kappaB-dependent manner. Cancer Cell. 2010;17:135-47.

26. Tape CJ, Ling S, Dimitriadi M, McMahon KM, Worboys JD, Leong HS, et al. Oncogenic KRAS regulates tumor cell signaling via stromal reciprocation. Cell. 2016;165:910-20.

27. Omary MB, Lugea A, Lowe AW, Pandol SJ. The pancreatic stellate cell: a star on the rise in pancreatic diseases. J Clin Invest. 2007;117:50-9.

28. Yin C, Evason KJ, Asahina K, Stainier DY. Hepatic stellate cells in liver development, regeneration, and cancer. J Clin Invest. 2013;123:1902-10.

29. Quante M, Tu SP, Tomita H, Gonda T, Wang SS, Takashi S, et al. Bone marrow-derived myofibroblasts contribute to the mesenchymal stem cell niche and promote tumor growth. Cancer Cell. 2011;19:257-72.

30. Raz Y, Cohen N, Shani O, Bell RE, Novitskiy SV, Abramovitz L, et al. Bone marrow-derived fibroblasts are a functionally distinct stromal cell population in breast cancer. J Exp Med. 2018;215:3075-93.

31. Weber CE, Kothari AN, Wai PY, Li NY, Driver J, Zapf MA, et al. Osteopontin mediates an MZF1-TGF-beta1-dependent transformation of mesenchymal stem cells into cancer-associated fibroblasts in breast cancer. Oncogene. 2015;34:4821-33.

32. Ko SY, Barengo N, Ladanyi A, Lee JS, Marini F, Lengyel E, et al. HOXA9 promotes ovarian cancer growth by stimulating cancer-associated fibroblasts. J Clin Invest. 2012;122:3603-17.

33. Jung Y, Kim JK, Shiozawa Y, Wang J, Mishra A, Joseph J, et al. Recruitment of mesenchymal stem cells into prostate tumours promotes metastasis. Nat Commun. 2013;4:1795.

34. Shi Y, Du L, Lin L, Wang Y. Tumour-associated mesenchymal stem/ stromal cells: emerging therapeutic targets. Nat Rev Drug Discov. 2017;16:35-52.

35. Rhim AD, Mirek ET, Aiello NM, Maitra A, Bailey JM, McAllister F, et al. EMT and dissemination precede pancreatic tumor formation. Cell. 2012;148:349-61.

36. Fischer KR, Durrans A, Lee S, Sheng J, Li F, Wong ST, et al. Epithelialto-mesenchymal transition is not required for lung metastasis but contributes to chemoresistance. Nature. 2015;527:472-6.

37. Potenta S, Zeisberg E, Kalluri R. The role of endothelial-to-mesenchymal transition in cancer progression. Br J Cancer. 2008;99:1375-9.

38. Jotzu C, Alt E, Welte G, Li J, Hennessy BT, Devarajan E, et al. Adipose tissue derived stem cells differentiate into carcinoma-associated fibroblast-like cells under the influence of tumor derived factors. Cell Oncol (Dordr). 2011;34:55-67.

39. Dulauroy S, Di Carlo SE, Langa F, Eberl G, Peduto L. Lineage tracing and genetic ablation of ADAM12(+) perivascular cells identify a major source of profibrotic cells during acute tissue injury. Nat Med. 2012;18:1262-70.

40. Rinkevich Y, Mori T, Sahoo D, Xu PX, Bermingham JR Jr, Weissman IL. Identification and prospective isolation of a mesothelial precursor lineage giving rise to smooth muscle cells and fibroblasts for mammalian internal organs, and their vasculature. Nat Cell Biol. 2012;14:1251-60.

41. Zeisberg EM, Potenta S, Xie L, Zeisberg M, Kalluri R. Discovery of endothelial to mesenchymal transition as a source for carcinomaassociated fibroblasts. Cancer Res. 2007;67:10123-8.

42. Kalluri $R$, Weinberg RA. The basics of epithelial-mesenchymal transition. J Clin Invest. 2009;1 19:1420-8.

43. Erkan M, Michalski CW, Rieder S, Reiser-Erkan C, Abiatari I, Kolb A, et al. The activated stroma index is a novel and independent prognostic marker in pancreatic ductal adenocarcinoma. Clin Gastroenterol Hepatol. 2008;6:1155-61.

44. Micallef L, Vedrenne N, Billet F, Coulomb B, Darby IA, Desmouliere A. The myofibroblast, multiple origins for major roles in normal and pathological tissue repair. Fibrogenesis Tissue Repair. 2012;5:S5.

45. Kuzet SE, Gaggioli C. Fibroblast activation in cancer: when seed fertilizes soil. Cell Tissue Res. 2016;365:607-19.

46. Yoshida N, Masamune A, Hamada S, Kikuta K, Takikawa T, Motoi F, et al. Kindlin-2 in pancreatic stellate cells promotes the progression of pancreatic cancer. Cancer Lett. 2017;390:103-14.

47. Sun Q, Zhang B, Hu Q, Qin Y, Xu W, Liu W, et al. The impact of cancerassociated fibroblasts on major hallmarks of pancreatic cancer. Theranostics. 2018;8:5072-87.
48. Alcolea MP, Jones PH. Tracking cells in their native habitat: lineage tracing in epithelial neoplasia. Nat Rev Cancer. 2013;13:161-71.

49. LeBleu VS, Taduri G, O'Connell J, Teng Y, Cooke VG, Woda C, et al. Origin and function of myofibroblasts in kidney fibrosis. Nat Med. 2013;19:1047-53.

50. Ozdemir BC, Pentcheva-Hoang T, Carstens JL, Zheng X, Wu CC, Simpson $T R$, et al. Depletion of carcinoma-associated fibroblasts and fibrosis induces immunosuppression and accelerates pancreas cancer with reduced survival. Cancer Cell. 2015;28:831-3.

51. Elyada E, Bolisetty M, Laise P, Flynn WF, Courtois ET, Burkhart RA, et al. Cross-species single-cell analysis of pancreatic ductal adenocarcinoma reveals antigen-presenting cancer-associated fibroblasts. Cancer Discov. 2019;9:1102-23.

52. Neuzillet C, Tijeras-Raballand A, Ragulan C, Cros J, Patil Y, Martinet M, et al. Inter- and intra-tumoural heterogeneity in cancer-associated fibroblasts of human pancreatic ductal adenocarcinoma. J Pathol. 2019;248:51-65.

53. Costa A, Kieffer Y, Scholer-Dahirel A, Pelon F, Bourachot B, Cardon M, et al. Fibroblast heterogeneity and immunosuppressive environment in human breast cancer. Cancer Cell. 2018:33(463-79):e10.

54. Rhim AD, Oberstein PE, Thomas DH, Mirek ET, Palermo CF, Sastra SA, et al. Stromal elements act to restrain, rather than support, pancreatic ductal adenocarcinoma. Cancer Cell. 2014;25:735-47.

55. Brechbuhl HM, Finlay-Schultz J, Yamamoto TM, Gillen AE, Cittelly DM, Tan AC, et al. Fibroblast subtypes regulate responsiveness of luminal breast cancer to estrogen. Clin Cancer Res. 2017;23:1710-21.

56. Givel AM, Kieffer Y, Scholer-Dahirel A, Sirven P, Cardon M, Pelon F, et al. miR200-regulated CXCL12 $\beta$ promotes fibroblast heterogeneity and immunosuppression in ovarian cancers. Nat Commun. 2018;9:1056

57. Yoshida GJ. Regulation of heterogeneous cancer-associated fibroblasts: the molecular pathology of activated signaling pathways. J Exp Clin Cancer Res. 2020;39:112.

58. Biffi G, Oni TE, Spielman B, Hao Y, Elyada E, Park Y, et al. IL1-Induced JAK/ STAT signaling is antagonized by TGFbeta to shape CAF heterogeneity in pancreatic ductal adenocarcinoma. Cancer Discov. 2019a;9:282-301.

59. Nardi F, Fitchev P, Franco OE, Ivanisevic J, Scheibler A, Hayward SW, et al. PEDF regulates plasticity of a novel lipid-MTOC axis in prostate cancerassociated fibroblasts. J Cell Sci. 2018;131:jcs213579.

60. Biffi G, Oni TE, Spielman B, Hao Y, Elyada E, Park Y, et al. IL 1-Induced JAK/ STAT signaling is antagonized by TGF $\beta$ to shape CAF Heterogeneity in Pancreatic Ductal Adenocarcinoma. Cancer Discov. 2019b;9:282-301.

61. Vennin C, Melenec P, Rouet R, Nobis M, Cazet AS, Murphy KJ, et al. CAF hierarchy driven by pancreatic cancer cell p53-status creates a pro-metastatic and chemoresistant environment via perlecan. Nat Commun. 2019;10:3637.

62. Bartel DP. Metazoan microRNAs. Cell. 2018;173:20-51.

63. Lee Y, Kim M, Han J, Yeom KH, Lee S, Baek SH, et al. MicroRNA genes are transcribed by RNA polymerase II. Embo j. 2004;23:4051-60.

64. Borchert GM, Lanier W, Davidson BL. RNA polymerase III transcribes human microRNAs. Nat Struct Mol Biol. 2006;13:1097-101.

65. Lee Y, Ahn C, Han J, Choi H, Kim J, Yim J, et al. The nuclear RNase III Drosha initiates microRNA processing. Nature. 2003;425:415-9.

66. Han J, Lee Y, Yeom KH, Nam JW, Heo I, Rhee JK, et al. Molecular basis for the recognition of primary microRNAs by the Drosha-DGCR8 complex. Cell. 2006;125:887-901.

67. Yi R, Qin Y, Macara IG, Cullen BR. Exportin-5 mediates the nuclear export of pre-microRNAs and short hairpin RNAs. Genes Dev. 2003;17:3011-6.

68. Lund E, Guttinger S, Calado A, Dahlberg JE, Kutay U. Nuclear export of microRNA precursors. Science. 2004;303:95-8.

69. Bernstein E, Caudy AA, Hammond SM, Hannon GJ. Role for a bidentate ribonuclease in the initiation step of RNA interference. Nature. 2001;409:363-6.

70. Gregory RI, Chendrimada TP, Cooch N, Shiekhattar R. Human RISC couples microRNA biogenesis and posttranscriptional gene silencing. Cell. 2005;123:631-40.

71. Bartel DP. MicroRNAs: genomics, biogenesis, mechanism, and function. Cell. 2004;116:281-97.

72. Filipowicz W, Bhattacharyya SN, Sonenberg N. Mechanisms of posttranscriptional regulation by microRNAs: are the answers in sight? Nat Rev Genet. 2008;9:102-14. 
73. Lee I, Ajay SS, Yook Jl, Kim HS, Hong SH, Kim NH, et al. New class of microRNA targets containing simultaneous 5'-UTR and 3'-UTR interaction sites. Genome Res. 2009;19:1175-83.

74. Fabbri M, Paone A, Calore F, Galli R, Croce CM. A new role for microRNAs, as ligands of Toll-like receptors. RNA Biol. 2013;10:169-74.

75. Dragomir MP, Knutsen E, Calin GA. SnapShot: unconventional miRNA functions. Cell. 2018;174:1038-e1.

76. Albrengues J, Bertero T, Grasset E, Bonan S, Maiel M, Bourget I, et al. Epigenetic switch drives the conversion of fibroblasts into proinvasive cancer-associated fibroblasts. Nat Commun. 2015;6:10204.

77. Laklai H, Miroshnikova YA, Pickup MW, Collisson EA, Kim GE, Barrett AS, et al. Genotype tunes pancreatic ductal adenocarcinoma tissue tension to induce matricellular fibrosis and tumor progression. Nat Med. 2016:22:497-505.

78. Wormann SM, Song L, Ai J, Diakopoulos KN, Kurkowski MU, Gorgulu K, et al. Loss of P53 function activates JAK2-STAT3 signaling to promote pancreatic tumor growth, stroma modification, and gemcitabine resistance in mice and is associated with patient survival. Gastroenterology. 2016;151(180-93):e12.

79. Roshani R, McCarthy F, Hagemann T. Inflammatory cytokines in human pancreatic cancer. Cancer Lett. 2014;345:157-63.

80. Zhao L, Sun Y, Hou Y, Peng Q, Wang L, Luo H, et al. MiRNA expression analysis of cancer-associated fibroblasts and normal fibroblasts in breast cancer. Int J Biochem Cell Biol. 2012;44:2051-9.

81. Mitra AK, Zillhardt M, Hua Y, Tiwari P, Murmann AE, Peter ME, et al. MicroRNAs reprogram normal fibroblasts into cancer-associated fibroblasts in ovarian cancer. Cancer Discov. 2012;2:1100-8.

82. Zhang J, Liu J, Liu Y, Wu W, Li X, Wu Y, et al. miR-101 represses lung cancer by inhibiting interaction of fibroblasts and cancer cells by downregulating CXCL12. Biomed Pharmacother. 2015;74:215-21.

83. Bullock MD, Pickard KM, Nielsen BS, Sayan AE, Jenei $V$, Mellone $M$, et al. Pleiotropic actions of miR-21 highlight the critical role of deregulated stromal microRNAs during colorectal cancer progression. Cell Death Dis. 2013;4:e684.

84. Schipper J, Westerhuis JJ, Beddows I, Madaj Z, Monsma D, Hostetter G, et al. Loss of microRNA-21 leads to profound stromal remodeling and short survival in K-Ras-driven mouse models of pancreatic cancer. Int J Cancer. 2020.

85. Tang X, Tu G, Yang G, Wang X, Kang L, Yang L, et al. Autocrine TGFbeta1/miR-200s/miR-221/DNMT3B regulatory loop maintains CAF status to fuel breast cancer cell proliferation. Cancer Lett. 2019a;452:79-89.

86. Doldi V, Callari M, Giannoni E, D'Aiuto F, Maffezzini M, Valdagni R, et al. Integrated gene and miRNA expression analysis of prostate cancer associated fibroblasts supports a prominent role for interleukin-6 in fibroblast activation. Oncotarget. 2015;6:31441-60.

87. Li P, Shan JX, Chen XH, Zhang D, Su LP, Huang XY, et al. Epigenetic silencing of microRNA-149 in cancer-associated fibroblasts mediates prostaglandin E2/interleukin-6 signaling in the tumor microenvironment. Cell Res. 2015;25:588-603.

88. Gandellini P, Giannoni E, Casamichele A, Taddei ML, Callari M, Piovan C, et al. miR-205 hinders the malignant interplay between prostate cancer cells and associated fibroblasts. Antioxid Redox Signal. 2014:20:1045-59.

89. Shen H, Yu X, Yang F, Zhang Z, Shen J, Sun J, et al. Reprogramming of normal fibroblasts into cancer-associated fibroblasts by miRNAs-mediated CCL2NEGFA signaling. PLoS Genet. 2016;12:e1006244.

90. Nie Y, Chen J, Huang D, Yao Y, Chen J, Ding L, et al. Tumor-associated macrophages promote malignant progression of breast phyllodes tumors by inducing myofibroblast differentiation. Cancer Res. 2017;77:3605-18.

91. Raposo G, Stoorvogel W. Extracellular vesicles: exosomes, microvesicles, and friends. J Cell Biol. 2013;200:373-83.

92. van Niel G, D'Angelo G, Raposo G. Shedding light on the cell biology of extracellular vesicles. Nat Rev Mol Cell Biol. 2018;19:213-28.

93. Penfornis P, Vallabhaneni KC, Whitt J, Pochampally R. Extracellular vesicles as carriers of microRNA, proteins and lipids in tumor microenvironment. Int J Cancer. 2016;138:14-21.

94. Bebelman MP, Smit MJ, Pegtel DM, Baglio SR. Biogenesis and function of extracellular vesicles in cancer. Pharmacol Ther. 2018;188:1-11.

95. Vu LT, Peng B, Zhang DX, Ma V, Mathey-Andrews CA, Lam CK, et al. Tumor-secreted extracellular vesicles promote the activation of cancer-associated fibroblasts via the transfer of microRNA-125b. J Extracell Vesicles. 2019;8:1599680.

96. Zhou Y, Ren H, Dai B, Li J, Shang L, Huang J, et al. Hepatocellular carcinoma-derived exosomal miRNA-21 contributes to tumor progression by converting hepatocyte stellate cells to cancer-associated fibroblasts. J Exp Clin Cancer Res. 2018;37:324.

97. Fang T, Lv H, Lv G, Li T, Wang C, Han Q, et al. Tumor-derived exosomal miR-1247-3p induces cancer-associated fibroblast activation to foster lung metastasis of liver cancer. Nat Commun. 2018;9:191.

98. Dror S, Sander L, Schwartz H, Sheinboim D, Barzilai A, Dishon Y, et al. Melanoma miRNA trafficking controls tumour primary niche formation. Nat Cell Biol. 2016:18:1006-17.

99. Guido C, Whitaker-Menezes D, Lin Z, Pestell RG, Howell A, Zimmers TA, et al. Mitochondrial fission induces glycolytic reprogramming in cancerassociated myofibroblasts, driving stromal lactate production, and early tumor growth. Oncotarget. 2012;3:798-810.

100. McAllister SS, Weinberg RA. The tumour-induced systemic environment as a critical regulator of cancer progression and metastasis. Nat Cell Biol. 2014;16:717-27.

101. Zhao H, Yang L, Baddour J, Achreja A, Bernard V, Moss T, et al. Tumor microenvironment derived exosomes pleiotropically modulate cancer cell metabolism. Elife. 2016;5:e10250.

102. Martinez-Outschoorn UE, Lin Z, Trimmer C, Flomenberg N, Wang C, Pavlides S, et al. Cancer cells metabolically "fertilize" the tumor microenvironment with hydrogen peroxide, driving the Warburg effect: implications for PET imaging of human tumors. Cell Cycle. 2011;10:2504-20.

103. Yan W, Wu X, Zhou W, Fong MY, Cao M, Liu J, et al. Cancer-cell-secreted exosomal miR-105 promotes tumour growth through the MYCdependent metabolic reprogramming of stromal cells. Nat Cell Biol. 2018;20:597-609.

104. Pavlides S, Whitaker-Menezes D, Castello-Cros R, Flomenberg N, Witkiewicz AK, Frank PG, et al. The reverse Warburg effect: aerobic glycolysis in cancer associated fibroblasts and the tumor stroma. Cell Cycle. 2009:8:3984-4001.

105. Taddei ML, Cavallini L, Comito G, Giannoni E, Folini M, Marini A, et al. Senescent stroma promotes prostate cancer progression: the role of miR-210. Mol Oncol. 2014;8:1729-46.

106. Zhang D, Wang Y, Shi Z, Liu J, Sun P, Hou X, et al. Metabolic reprogramming of cancer-associated fibroblasts by IDH3alpha downregulation. Cell Rep. 2015;10:1335-48.

107. Gascard P, TIsty TD. Carcinoma-associated fibroblasts: orchestrating the composition of malignancy. Genes Dev. 2016;30:1002-19.

108. Kalluri R, Zeisberg M. Fibroblasts in cancer. Nat Rev Cancer. 2006;6:392-401

109. Tang X, Tu G, Yang G, Wang X, Kang L, Yang L, et al. Autocrine TGF- $\beta 1$ / miR-200s/miR-221/DNMT3B regulatory loop maintains CAF status to fuel breast cancer cell proliferation. Cancer Lett. 2019b;452:79-89.

110. Cohen JD, Javed AA, Thoburn C, Wong F, Tie J, Gibbs P, et al. Combined circulating tumor DNA and protein biomarker-based liquid biopsy for the earlier detection of pancreatic cancers. Proc Natl Acad Sci USA. 2017:114:10202-7.

111. Liu Y, Zhang J, Sun X, Su Q, You C. Down-regulation of miR-29b in carcinoma associated fibroblasts promotes cell growth and metastasis of breast cancer. Oncotarget. 2017;8:39559-70.

112. Musumeci M, Coppola V, Addario A, Patrizii M, Maugeri-Saccà M, Memeo L, et al. Control of tumor and microenvironment cross-talk by miR-15a and miR-16 in prostate cancer. Oncogene. 2011;30:4231-42.

113. Sun Y, Yang D, Xi L, Chen Y, Fu L, Sun K, et al. Primed atypical ductal hyperplasia-associated fibroblasts promote cell growth and polarity changes of transformed epithelium-like breast cancer MCF-7 cells via miR-200b/c-IKKß signaling. Cell Death Dis. 2018a;9:122.

114. Shen Z, Qin X, Yan M, Li R, Chen G, Zhang J, et al. Cancer-associated fibroblasts promote cancer cell growth through a miR-7-RASSF2-PAR-4 axis in the tumor microenvironment. Oncotarget. 2017:8:1290-303.

115. Kim JE, Kim BG, Jang Y, Kang S, Lee JH, Cho NH. The stromal loss of miR4516 promotes the FOSL1-dependent proliferation and malignancy of triple negative breast cancer. Cancer Lett. 2020;469:256-65.

116. Wang X, Qin X, Yan M, Shi J, Xu Q, Li Z, et al. Loss of exosomal miR-3188 in cancer-associated fibroblasts contributes to HNC progression. J Exp Clin Cancer Res. 2019;38:151. 
117. Zhang Z, Li X, Sun W, Yue S, Yang J, Li J, et al. Loss of exosomal miR-320a from cancer-associated fibroblasts contributes to HCC proliferation and metastasis. Cancer Lett. 2017;397:33-42.

118. Xu G, Zhang B, Ye J, Cao S, Shi J, Zhao Y, et al. Exosomal miRNA-139 in cancer-associated fibroblasts inhibits gastric cancer progression by repressing MMP11 expression. Int J Biol Sci. 2019;15:2320-9.

119. Richards KE, Zeleniak AE, Fishel ML, Wu J, Littlepage LE, Hill R. Cancerassociated fibroblast exosomes regulate survival and proliferation of pancreatic cancer cells. Oncogene. 2017;36:1770-8.

120. Pereira BA, Vennin C, Papanicolaou M, Chambers CR, Herrmann D, Morton JP, et al. CAF subpopulations: a new reservoir of stromal targets in pancreatic cancer. Trends Cancer. 2019;5:724-41.

121. Donnarumma E, Fiore D, Nappa M, Roscigno G, Adamo A, laboni $\mathrm{M}$, et al. Cancer-associated fibroblasts release exosomal microRNAs that dictate an aggressive phenotype in breast cancer. Oncotarget. 2017:8:19592-608.

122. Hu JL, Wang W, Lan XL, Zeng ZC, Liang YS, Yan YR, et al. CAFs secreted exosomes promote metastasis and chemotherapy resistance by enhancing cell stemness and epithelial-mesenchymal transition in colorectal cancer. Mol Cancer. 2019;18:91.

123. Taddei ML, Cavallini L, Ramazzotti M, Comito G, Pietrovito L, Morandi A, et al. Stromal-induced downregulation of miR-1247 promotes prostate cancer malignancy. J Cell Physiol. 2019;234:8274-85.

124. Hanahan D, Weinberg RA. Hallmarks of cancer: the next generation. Cell. 2011;144:646-74.

125. Warburg O. The metabolism of tumors in the boDY. J Gen Physiol. 1927:8:519-30.

126. Vander Heiden MG, Cantley LC, Thompson CB. Understanding the Warburg effect: the metabolic requirements of cell proliferation. Science. 2009:324:1029-33.

127. Zhang $H$, Deng $T$, Liu $R$, Ning T, Yang H, Liu D, et al. CAF secreted miR522 suppresses ferroptosis and promotes acquired chemo-resistance in gastric cancer. Mol Cancer. 2020;19:43.

128. Naumov GN, Akslen LA, Folkman J. Role of angiogenesis in human tumor dormancy: animal models of the angiogenic switch. Cell Cycle. 2006;5:1779-87.

129. Crawford Y, Kasman I, Yu L, Zhong C, Wu X, Modrusan Z, et al. PDGF-C mediates the angiogenic and tumorigenic properties of fibroblasts associated with tumors refractory to anti-VEGF treatment. Cancer Cell. 2009:15:21-34

130. De Palma M, Biziato D, Petrova TV. Microenvironmental regulation of tumour angiogenesis. Nat Rev Cancer. 2017:17:457-74.

131. Zhou B, Ma R, Si W, Li S, Xu Y, Tu X, et al. MicroRNA-503 targets FGF2 and VEGFA and inhibits tumor angiogenesis and growth. Cancer Lett. 2013;333:159-69.

132. Png KJ, Halberg N, Yoshida M, Tavazoie SF. A microRNA regulon that mediates endothelial recruitment and metastasis by cancer cells. Nature. 2011;481:190-4

133. Zhou X, Yan T, Huang C, Xu Z, Wang L, Jiang E, et al. Melanoma cellsecreted exosomal miR-155-5p induce proangiogenic switch of cancerassociated fibroblasts via SOCS1/JAK2/STAT3 signaling pathway. J Exp Clin Cancer Res. 2018;37:242.

134. Fan J, Xu G, Chang Z, Zhu L, Yao J. miR-210 transferred by lung cancer cell-derived exosomes may act as proangiogenic factor in cancer-associated fibroblasts by modulating JAK2/STAT3 pathway. Clin Sci (Lond). 2020;134:807-25

135. Du YE, Tu G, Yang G, Li G, Yang D, Lang L, et al. MiR-205/YAP1 in Activated Fibroblasts of Breast Tumor Promotes VEGF-independent Angiogenesis through STAT3 Signaling. Theranostics. 2017;7:3972-88.

136. Yoshida GJ, Azuma A, Miura Y, Orimo A. Activated fibroblast program orchestrates tumor initiation and progression; molecular mechanisms and the associated therapeutic strategies. Int J Mol Sci. 2019;20:2256.

137. Grasset EM, Bertero T, Bozec A, Friard J, Bourget I, Pisano S, et al. Matrix Stiffening and EGFR cooperate to promote the collective invasion of cancer cells. Cancer Res. 2018;78:5229-42.

138. Tang X, Hou Y, Yang G, Wang X, Tang S, Du YE, et al. Stromal miR-200s contribute to breast cancer cell invasion through CAF activation and ECM remodeling. Cell Death Differ. 2016;23:132-45.

139. Ast V, Kordaß T, Oswald M, Kolte A, Eisel D, Osen W, et al. MiR-192, miR200c and miR-17 are fibroblast-mediated inhibitors of colorectal cancer invasion. Oncotarget. 2018;9:35559-80.
140. Utaijaratrasmi P, Vaeteewoottacharn K, Tsunematsu T, Jamjantra P, Wongkham S, Pairojkul C, et al. The microRNA-15a-PAl-2 axis in cholangiocarcinoma-associated fibroblasts promotes migration of cancer cells. Mol Cancer. 2018;17:10.

141. Aprelikova O, Palla J, Hibler B, Yu X, Greer YE, Yi M, et al. Silencing of miR-148a in cancer-associated fibroblasts results in WNT10B-mediated stimulation of tumor cell motility. Oncogene. 2013;32:3246-53.

142. Dongre A, Weinberg RA. New insights into the mechanisms of epithelial-mesenchymal transition and implications for cancer. Nat Rev Mol Cell Biol. 2019;20:69-84.

143. Wang R, Sun Y, Yu W, Yan Y, Qiao M, Jiang R, et al. Downregulation of miRNA-214 in cancer-associated fibroblasts contributes to migration and invasion of gastric cancer cells through targeting FGF9 and inducing EMT. J Exp Clin Cancer Res. 2019:38:20.

144. Wang H, Wei H, Wang J, Li L, Chen A, Li Z. MicroRNA-181d-5pcontaining exosomes derived from CAFs promote EMT by regulating $\mathrm{CDX} 2 / \mathrm{HOXA} 5$ in breast cancer. Mol Ther Nucleic Acids. 2020;19:654-67.

145. Li BL, Lu W, Qu JJ, Ye L, Du GQ, Wan XP. Loss of exosomal miR-148b from cancer-associated fibroblasts promotes endometrial cancer cell invasion and cancer metastasis. J Cell Physiol. 2019;234:2943-53.

146. Yang F, Yan Y, Yang Y, Hong X, Wang M, Yang Z, et al. MiR-210 in exosomes derived from CAFs promotes non-small cell lung cancer migration and invasion through PTEN/PI3K/AKT pathway. Cell Signal. 2020;73:109675.

147. Li YY, Tao YW, Gao S, Li P, Zheng JM, Zhang SE, et al. Cancer-associated fibroblasts contribute to oral cancer cells proliferation and metastasis via exosome-mediated paracrine miR-34a-5p. EBioMedicine. 2018;36:209-20.

148. Wu HJ, Hao M, Yeo SK, Guan JL. FAK signaling in cancer-associated fibroblasts promotes breast cancer cell migration and metastasis by exosomal miRNAs-mediated intercellular communication. Oncogene. 2020;39:2539-49.

149. Liu Y, Yang Y, Du J, Lin D, Li F. MiR-3613-3p from carcinoma-associated fibroblasts exosomes promoted breast cancer cell proliferation and metastasis by regulating SOCS2 expression. IUBMB Life. 2020;72:1705-14

150. Wang JW, Wu XF, Gu XJ, Jiang XH. Exosomal miR-1228 from cancerassociated fibroblasts promotes cell migration and invasion of osteosarcoma by directly targeting SCAI. Oncol Res. 2019;27:979-86.

151. Bhome R, Goh RW, Bullock MD, Pillar N, Thirdborough SM, Mellone M, et al. Exosomal microRNAs derived from colorectal cancer-associated fibroblasts: role in driving cancer progression. Aging (Albany NY). 2017:9:2666-94

152. Holohan C, Van Schaeybroeck S, Longley DB, Johnston PG. Cancer drug resistance: an evolving paradigm. Nat Rev Cancer. 2013;13:714-26.

153. Fiori ME, Di Franco S, Villanova L, Bianca P, Stassi G, De Maria R. Cancer-associated fibroblasts as abettors of tumor progression at the crossroads of EMT and therapy resistance. Mol Cancer. 2019;18:70.

154. Zhang L, Yao J, Li W, Zhang C. Micro-RNA-21 regulates cancer-associated fibroblast-mediated drug resistance in pancreatic cancer. Oncol Res. 2018;26:827-35.

155. Li J, Guan J, Long X, Wang Y, Xiang X. mir-1-mediated paracrine effect of cancer-associated fibroblasts on lung cancer cell proliferation and chemoresistance. Oncol Rep. 2016;35:3523-31.

156. Tanaka K, Miyata H, Sugimura K, Fukuda S, Kanemura T, Yamashita K et al. miR-27 is associated with chemoresistance in esophageal cancer through transformation of normal fibroblasts to cancer-associated fibroblasts. Carcinogenesis. 2015;36:894-903.

157. Qin X, Guo H, Wang X, Zhu X, Yan M, Wang X, et al. Exosomal miR-196a derived from cancer-associated fibroblasts confers cisplatin resistance in head and neck cancer through targeting CDKN1B and ING5. Genome Biol. 2019;20:12.

158. Au Yeung CL, Co NN, Tsuruga T, Yeung TL, Kwan SY, Leung CS, et al. Exosomal transfer of stroma-derived miR21 confers paclitaxel resistance in ovarian cancer cells through targeting APAF1. Nat Commun. 2016:7:11150.

159. Guo H, Ha C, Dong H, Yang Z, Ma Y, Ding Y. Cancer-associated fibroblastderived exosomal microRNA-98-5p promotes cisplatin resistance in ovarian cancer by targeting CDKN1A. Cancer Cell Int. 2019;19:347. 
160. Fang Y, Zhou W, Rong Y, Kuang T, Xu X, Wu W, et al. Exosomal miRNA$106 \mathrm{~b}$ from cancer-associated fibroblast promotes gemcitabine resistance in pancreatic cancer. Exp Cell Res. 2019;383:111543.

161. Barrett R, Puré E. Cancer-associated fibroblasts: key determinants of tumor immunity and immunotherapy. Curr Opin Immunol. 2020;64:80-7.

162. An Y, Liu F, Chen Y, Yang Q. Crosstalk between cancer-associated fibroblasts and immune cells in cancer. J Cell Mol Med. 2020;24:13-24.

163. Hilmi M, Nicolle R, Bousquet C, Neuzillet C. Cancer-associated fibroblasts: accomplices in the tumor immune evasion. Cancers Basel. 2020;12:2969

164. Liu T, Han C, Wang S, Fang P, Ma Z, Xu L, et al. Cancer-associated fibroblasts: an emerging target of anti-cancer immunotherapy. J Hematol Oncol. 2019:12:86.

165. Domvri K, Petanidis S, Anestakis D, Porpodis K, Bai C, Zarogoulidis $\mathrm{P}$, et al. Exosomal IncRNA PCAT-1 promotes Kras-associated chemoresistance via immunosuppressive miR-182/miR-217 signaling and p27/ CDK6 regulation. Oncotarget. 2020;11:2847-62.

166. Lee KS, Nam SK, Koh J, Kim DW, Kang SB, Choe G, et al. Stromal expression of microRNA-21 in advanced colorectal cancer patients with distant metastases. J Pathol Transl Med. 2016;50:270-7.

167. Kunita A, Morita S, Irisa TU, Goto A, Niki T, Takai D, et al. MicroRNA-21 in cancer-associated fibroblasts supports lung adenocarcinoma progression. Sci Rep. 2018:8:8838.

168. Kadera BE, Li L, Toste PA, Wu N, Adams C, Dawson DW, et al. MicroRNA-21 in pancreatic ductal adenocarcinoma tumor-associated fibroblasts promotes metastasis. PLoS ONE. 2013;8:e71978.

169. Ren Y, Zhou X, Liu X, Jia HH, Zhao XH, Wang QX, et al. Reprogramming carcinoma associated fibroblasts by AC1MMYR2 impedes tumor metastasis and improves chemotherapy efficacy. Cancer Lett. 2016:374:96-106.

170. Lai X, Eberhardt M, Schmitz U, Vera J. Systems biology-based investigation of cooperating microRNAs as monotherapy or adjuvant therapy in cancer. Nucleic Acids Res. 2019;47:7753-66.

171. Lee TJ, Yuan X, Kerr K, Yoo JY, Kim DH, Kaur B, et al. Strategies to modulate microRNA functions for the treatment of cancer or organ injury. Pharmacol Rev. 2020;72:639-67.

172. Rashed MH, Bayraktar E, Helal KH, Abd-Ellah MF, Amero P, Chavez-Reyes A, et al. Exosomes: from garbage bins to promising therapeutic targets. Int J Mol Sci. 2017;18:538.

173. Marleau AM, Chen CS, Joyce JA, Tullis RH. Exosome removal as a therapeutic adjuvant in cancer. J Transl Med. 2012;10:134.

174. Wang F, Li L, Piontek K, Sakaguchi M, Selaru FM. Exosome miR-335 as a novel therapeutic strategy in hepatocellular carcinoma. Hepatology. 2018;67:940-54

175. Li L, Piontek K, Ishida M, Fausther M, Dranoff JA, Fu R, et al. Extracellular vesicles carry microRNA-195 to intrahepatic cholangiocarcinoma and improve survival in a rat model. Hepatology. 2017;65:501-14.

176. Ulitsky I, Bartel DP. lincRNAs: genomics, evolution, and mechanisms. Cell. 2013;154:26-46.

177. Katayama S, Tomaru Y, Kasukawa T, Waki K, Nakanishi M, Nakamura M, et al. Antisense transcription in the mammalian transcriptome. Science. 2005:309:1564-6.

178. Quinn JJ, Chang HY. Unique features of long non-coding RNA biogenesis and function. Nat Rev Genet. 2016;17:47-62.

179. Xing YH, Chen LL. Processing and roles of snoRNA-ended long noncoding RNAs. Crit Rev Biochem Mol Biol. 2018;53:596-606.

180. Ransohoff JD, Wei Y, Khavari PA. The functions and unique features of long intergenic non-coding RNA. Nat Rev Mol Cell Biol. 2018;19:143-57.

181. Rinn JL. IncRNAs: linking RNA to chromatin. Cold Spring Harb Perspect Biol. 2014;6:538

182. Ponting CP, Oliver PL, Reik W. Evolution and functions of long noncoding RNAs. Cell. 2009;136:629-41.

183. Mercer TR, Dinger ME, Mattick JS. Long non-coding RNAs: insights into functions. Nat Rev Genet. 2009;10:155-9.

184. Santos-Pereira JM, Aguilera A. R loops: new modulators of genome dynamics and function. Nat Rev Genet. 2015;16:583-97.

185. Li Y, Syed J, Sugiyama H. RNA-DNA triplex formation by long noncoding RNAs. Cell Chem Biol. 2016:23:1325-33.
186. Ingolia NT, Brar GA, Stern-Ginossar N, Harris MS, Talhouarne GJ, Jackson $\mathrm{SE}$, et al. Ribosome profiling reveals pervasive translation outside of annotated protein-coding genes. Cell Rep. 2014;8:1365-79.

187. Walters K, Sarsenov R, Too WS, Hare RK, Paterson IC, Lambert DW, et al. Comprehensive functional profiling of long non-coding RNAs through a novel pan-cancer integration approach and modular analysis of their protein-coding gene association networks. BMC Genomics. 2019;20:454.

188. Ding L, Ren J, Zhang D, Li Y, Huang X, Hu Q, et al. A novel stromal IncRNA signature reprograms fibroblasts to promote the growth of oral squamous cell carcinoma via LncRNA-CAF/interleukin-33. Carcinogenesis. 2018:39:397-406

189. HuT, Hu J. Melanoma-derived exosomes induce reprogramming fibroblasts into cancer-associated fibroblasts via Gm26809 delivery. Cell Cycle. 2019;18:3085-94.

190. Sun Z, Yang S, Zhou Q, Wang G, Song J, Li Z, et al. Emerging role of exosome-derived long non-coding RNAs in tumor microenvironment. Mol Cancer. 2018;17:82.

191. Chen D, LuT, Tan J, Li H, Wang Q, Wei L. Long non-coding RNAs as communicators and mediators between the tumor microenvironment and cancer cells. Front Oncol. 2019;9:739.

192. Vafaee F, Colvin EK, Mok SC, Howell VM, Samimi G. Functional prediction of long non-coding RNAs in ovarian cancer-associated fibroblasts indicate a potential role in metastasis. Sci Rep. 2017;7:10374.

193. Zhang S, Tao X, Cao Q, Feng X, Wu J, Yu H, et al. Inc003875/miR-363/ EGR1 regulatory network in the carcinoma -associated fibroblasts controls the angiogenesis of human placental site trophoblastic tumor (PSTT). Exp Cell Res. 2020;387:111783.

194. Jin N, Jin N, Bu W, Li X, Liu L, Wang Z, et al. Long non-coding RNA TIRY promotes tumor metastasis by enhancing epithelial-to-mesenchymal transition in oral cancer. Exp Biol Med (Maywood). 2020:245:585-96.

195. Zhao L, Ji G, Le X, Wang C, Xu L, Feng M, et al. Long noncoding RNA LINC00092 acts in cancer-associated fibroblasts to drive glycolysis and progression of ovarian cancer. Cancer Res. 2017;77:1369-82.

196. Li Y, Zhao Z, Liu W, Li X. SNHG3 functions as miRNA sponge to promote breast cancer cells growth through the metabolic reprogramming. Appl Biochem Biotechnol. 2020;191:1084-99.

197. Ren J, Ding L, Zhang D, Shi G, Xu Q, Shen S, et al. Carcinoma-associated fibroblasts promote the stemness and chemoresistance of colorectal cancer by transferring exosomal IncRNA H19. Theranostics. 2018;8:3932-48.

198. Deng X, Ruan H, Zhang X, Xu X, Zhu Y, Peng H, et al. Long noncoding RNA CCAL transferred from fibroblasts by exosomes promotes chemoresistance of colorectal cancer cells. Int J Cancer. 2020;146:1700-16.

199. Colvin EK, Howell VM, Mok SC, Samimi G, Vafaee F. Expression of long noncoding RNAs in cancer-associated fibroblasts linked to patient survival in ovarian cancer. Cancer Sci. 2020:111:1805-17.

200. $\mathrm{Li} \mathrm{CH}$, Chen Y. Targeting long non-coding RNAs in cancers: progress and prospects. Int J Biochem Cell Biol. 2013:45:1895-910.

201. Arun G, Diermeier SD, Spector DL. Therapeutic targeting of long noncoding RNAs in cancer. Trends Mol Med. 2018;24:257-77.

202. Chatterjee A, Jana S, Chatterjee S, Wastall LM, Mandal G, Nargis N, et al. MicroRNA-222 reprogrammed cancer-associated fibroblasts enhance growth and metastasis of breast cancer. Br J Cancer. 2019;121:679-89.

203. Sun Y, Yang D, Xi L, Chen Y, Fu L, Sun K, et al. Primed atypical ductal hyperplasia-associated fibroblasts promote cell growth and polarity changes of transformed epithelium-like breast cancer MCF-7 cells via miR-200b/c-IKKbeta signaling. Cell Death Dis. 2018b;9:122.

204. Li Q, Zhang D, Wang Y, Sun P, Hou X, Larner J, et al. MiR-21/Smad 7 signaling determines TGF-beta1-induced CAF formation. Sci Rep. 2013;3:2038.

205. Yang SS, Ma S, Dou H, Liu F, Zhang SY, Jiang C, et al. Breast cancerderived exosomes regulate cell invasion and metastasis in breast cancer via miR-146a to activate cancer associated fibroblasts in tumor microenvironment. Exp Cell Res. 2020;391:111983.

206. Baroni S, Romero-Cordoba S, Plantamura I, Dugo M, D'Ippolito E, Cataldo A, et al. Exosome-mediated delivery of miR-9 induces cancerassociated fibroblast-like properties in human breast fibroblasts. Cell Death Dis. 2016;7:e2312. 
207. Pang W, Su J, Wang Y, Feng H, Dai X, Yuan Y, et al. Pancreatic cancersecreted miR-155 implicates in the conversion from normal fibroblasts to cancer-associated fibroblasts. Cancer Sci. 2015;106:1362-9.

208. Yang TS, Yang XH, Chen X, Wang XD, Hua J, Zhou DL, et al. MicroRNA$106 \mathrm{~b}$ in cancer-associated fibroblasts from gastric cancer promotes cell migration and invasion by targeting PTEN. FEBS Lett. 2014;588:2162-9.

209. Naito Y, Sakamoto N, Oue N, Yashiro M, Sentani K, Yanagihara K, et al, MicroRNA-143 regulates collagen type III expression in stromal fibroblasts of scirrhous type gastric cancer. Cancer Sci. 2014;105:228-35.

210. Naito Y, Yasuno K, Tagawa H, Sakamoto N, Oue N, Yashiro M, et al. MicroRNA-145 is a potential prognostic factor of scirrhous type gastric cancer. Oncol Rep. 2014;32:1720-6.
211. Chen Y, Du M, Wang J, Xing P, Zhang Y, Li F, et al. MiRNA-200a expression is inverse correlation with hepatocyte growth factor expression in stromal fibroblasts and its high expression predicts a good prognosis in patients with non-small cell lung cancer. Oncotarget. 2016;7:48432-42.

\section{Publisher's Note}

Springer Nature remains neutral with regard to jurisdictional claims in published maps and institutional affiliations.
Ready to submit your research? Choose BMC and benefit from:

- fast, convenient online submission

- thorough peer review by experienced researchers in your field

- rapid publication on acceptance

- support for research data, including large and complex data types

- gold Open Access which fosters wider collaboration and increased citations

- maximum visibility for your research: over $100 \mathrm{M}$ website views per year

At BMC, research is always in progress.

Learn more biomedcentral.com/submissions 